\title{
EL REFUERZO DEL DIÁLOGO ENTRE TRIBUNALES Y LA TRIPLE PREJUDICIALIDAD EN LA PROTECCIÓN DE LOS DERECHOS FUNDAMENTALES: EN TORNO AL PROTOCOLO N. ${ }^{\circ} 16$ AL CONVENIO EUROPEO DE DERECHOS HUMANOS
}

\author{
JUAN JOSÉ RUIZ RUIZ \\ Profesor Titular de Derecho Constitucional \\ Universidad de Jaén
}

\begin{abstract}
SUMARIO
I. Introducción. II. El contexto de elaboración del Protocolo n. ${ }^{\circ}$ 16. III. Naturaleza de la cuestión prejudicial ante el TEDH. IV. El diálogo entre tribunales y la triple prejudicialidad en la jurisdicción constitucional. V. Reflexión conclusiva.
\end{abstract}

\section{INTRODUCCIÓN}

El objeto de este trabajo incide en lo que entiendo será el nuevo proceso de reflexión que se habrá de afrontar en los próximos decenios en torno a las deficiencias y nuevas transformaciones del sistema de protección del Convenio Europeo de Derechos Humanos. En concreto el nuevo Protocolo 16 del Convenio, que entraba en vigor el 1 de agosto de 2018 y bautizado como el "protocolo del diálogo», incorpora una novedosa "vía incidental de diálogo» en el marco del control de convencionalidad, vía que viene a sumarse a las vías incidentales ya existentes en el marco de los controles de incidentales en aplicación del Derecho de la Unión Europea (UE) y en el marco del control de constitucionalidad.

Es mi intención por tanto dedicar especial atención a la creciente complejidad que la cuestión prejudicial convencional traerá en aquellos sistemas en los que hay una cuestión previa de constitucionalidad y la cuestión prejudicial en virtud del Derecho de la UE. El reenvío que incorpora el Protocolo 16 puede convertirse en una valiosa herramienta en el proceso de cooperación y propulsión de la coherencia del circuito jurisprudencial construido a partir de la circularidad de interpretaciones conformes de Tribunal Constitucional, Tribunal de Justicia de la UE y TEDH. La inserción de una nueva cuestión prejudicial no traerá por ello consigo una disminución en la autonomía del juez 
nacional, sino que debe ser vista como una garantía más de la triple tutela de derechos que se superponen y que tiene como regla esencial la del mejor standard de protección a partir de una disputa discursiva construida sobre la mejor solución.

La adopción de los Protocolos n. ${ }^{\circ} 15$ y n. ${ }^{\circ} 16$, cuya redacción fue encargada por el Comité de Ministros al término de la Conferencia de Brighton, ha culminado un nuevo proceso de reflexión sobre las deficiencias y transformaciones que habrá de afrontar en los próximos decenios el sistema de protección del Convenio Europeo de Derechos Humanos (en adelante, CEDH). A diferencia del Protocolo n. ${ }^{\circ} 15$, el Protocolo 16 ha sido elaborado por el Comité directivo a petición del Comité de Ministros como protocolo adicional $^{1}$. La entrada en vigor del Protocolo n. ${ }^{\circ}$ 16, adoptado el 28 de junio de 2013 por el Comité de Ministros, y abierto a su firma el 2 de octubre de 2013, tendrá lugar tan pronto lo ratifiquen diez estados ${ }^{2}$.

En virtud de este nuevo protocolo, los altos tribunales que indiquen los estados parte del Convenio (art. 10), podrán suspender el procedimiento y solicitar a la Gran Cámara que resuelva una duda sobre la interpretación o la aplicación de una norma convencional o sus protocolos adicionales. Así ha ocurrido ya con la primera cuestión elevada al TEDH por la Corte de Casación de Francia mediante el Arrêt n. ${ }^{\circ} 638$ de 5 de octubre de 2018 (10-19.053) y cuyo objeto es el art. 8 CEDF. La solicitud debe no obstante superar un filtro previo, ya que debe ser admitida por 5 jueces que en caso de rechazar la petición, deberán motivarlo debidamente. La resolución de la cuestión se sustancia en una opinión de la Gran Cámara, puesto que carecerá de carácter vinculante (art. 5 del Protocolo). De ahí no cabe deducir empero una competencia del juez nacional para contrariar el ámbito subjetivo o sustantivo de los estándares adoptados en la opinión consultiva ${ }^{3}$. Al contrario, es probable que en la práctica el juez nacional no se aparte de las conclusiones recogidas en el dictamen de la Gran Cámara, sobre todo en lo que se refiere a cuestiones aplicativas, dado que la opinión del TEDH no versará ni sobre hechos ni sobre cuestiones de Derecho interno ${ }^{4}$. En coherencia con su carácter no vinculante, queda a salvo la posibilidad para la persona que se considere lesionada en su derecho, de interponer recurso ante el TEDH (art. $34 \mathrm{CEDH}$ ), una vez concluido el proceso del que es parte, solo si el juez nacional se ha apartado del parecer emitido por la Gran Cámara, como expresamente ha reconocido el propio TEDH en su Reflection Paper ${ }^{5}$, redactado para expresar su punto de vista sobre el borrador del Protocolo 16.

Una de las consecuencias que tendrá el nuevo Protocolo 16 será la apertura que producirá este nuevo procedimiento en la función consultiva del TEDH, teniendo en cuenta

1 La adopción tuvo lugar en su 77. a sesión.

2 España al día de hoy no ha firmado el Protocolo 16. A 11 de octubre de 2018 ya lo habían firmado 21 Estados parte del Convenio (Albania, Armenia, Eslovaquia, Eslovenia, Estonia, Finlandia, Francia, Georgia, Grecia, Holanda, Italia, Luxemburgo, Moldavia, Noruega, Rumanía, San Marino, Turquía y Ucrania), y al haber sido ratificado por 10 de ellos (Albania, Armenia, Eslovenia, Estonia, Finlandia, Francia, Georgia, Lituania, San Marino y Ucrania), según exige su art. 8, entraba en vigor el 1 de agosto de 2018 con la ratificación de Francia.

3 A. Paprocka - M. ZiółKowski, «Advisory opinions under Protocol No. 16 to the European Convention on Human Rights», European Constitutional Law Review, Vol. 11, Issue 02, 2015, p. 291.

4 La extensión de la opinión será por dicho motivo más breve que la resolución a un caso contencioso, pero por el contrario será más densa en contenido al tratar sobre cuestiones de principio. Sicilianos, L.A. (2014): «L'élargissement de la compétence consultative de la Cour européenne des droits de l'homme. À propos du protocole n. ${ }^{\circ} 16$ à la Convention européenne des droits de l'homme», Revue trimestrielle de Droits de l'homme, n. ${ }^{\circ} 97$, p. 28.

5 Reflection Paper, § 45. 
que las opiniones que hasta ahora podía emanar el TEDH se encontraban configuradas de manera muy limitada y restrictiva en el art. $47 \mathrm{CEDH}$. Dicho precepto en efecto se ha venido erigiendo en el principal obstáculo a sortear para abrir una vía de consulta al Tribunal por parte de los órganos de la jurisdicción nacional sobre la interpretación del Convenio. Si bien de su enunciado se desprendía la atribución de una competencia consultiva al TEDH para «dar opiniones consultivas sobre cuestiones jurídicas relativas a la interpretación del Convenio y sus Protocolos», excluye que dichas opiniones puedan versar «sobre cuestiones que afecten al contenido o a la extensión de los derechos y libertades del título I del Convenio y sus protocolos, ni pueden afectar a otra cuestiones sobre las que el Tribunal o el Comité pudieran tener que conocer por la introducción de un recurso». Lo limitadísimo de esta competencia, que solo correspondía instar al Comité de Ministros, ha sido realmente factor clave para la elaboración del nuevo Protocolo, cuya necesidad venía siendo observada en trabajos doctrinales desde hace más de tres décadas ${ }^{6}$ en los que se apuntaba, no solo como deseable sino también como necesario, la introducción de un mecanismo prejudicial que sirviera para dotar de uniformidad la aplicación del CEDH, una vez que quedaba constatada la integración del Convenio como derecho interno de los estados parte.

En lo que aquí interesa, el nuevo Protocolo incorpora una novedosa «vía incidental de diálogo» en el marco del control de convencionalidad ${ }^{7}$, vía que viene a sumarse a las vías incidentales ya existentes en el marco de los controles de incidentales en aplicación del Derecho de la Unión Europea (UE) y el marco del control de constitucionalidad. De hecho, el anterior Presidente del TEDH, Dean Spielmann, ha bautizado el Protocolo 16 como el «protocolo del diálgoo» (the dialogue protocol). Se da satisfacción de este modo a lo que venía siendo sentido en la doctrina, si no como una exigencia, sí como una necesidad ${ }^{8}$, pues a pesar de que el diálogo directo con el TEDH no venía impuesto hasta ahora por el Convenio ni sus Protocolos, ni en el Reglamento interno del Tribunal, al igual que tampoco en las normas de los procesos nacionales, el TEDH necesita de la colaboración de tribunales constitucionales y otras altas cortes, ya se trate en la fase ascendente antes de dictar sentencia, ya en la fase descendente en la medida que estos ejercen de mediadores que influirán en la eficacia de sus decisiones. La comunicación entre los tribunales nacionales y TEDH adquiere de este modo naturaleza de obligación, bien que hasta ahora tácita o implícita, pero en todo caso imprescindible para ejercer con corrección la labor jurisdiccional ${ }^{9}$. La particularidad es que la nueva herramienta procesal de la cuestión consultiva actuará en ambas fases, ascendente y descendente, ya que este método dialógico permite conocer al TEDH la interpretación del órgano jurisdiccional nacional, quien a su vez, recibida la solución a la cuestión, puede aplicarla al caso que debe juzgar. Ello entraña además un diálogo directo y

6 A.H., Robertson, «Advisory Opinions of the Court of Human Rights», AA.VV. René Cassin. Amicorum discipulorumque liber, vol. I, Paris, Editions A. Pédone, p. 225. Vid. asimismo D. SPIELMANN, «Quelques réflexions au sujet d'un recours préjudiciel éventuel devant la Cour européenne des droits de l'homme», Boletim do Ministério da Justiça, $\mathrm{n}^{\circ} .31 / 32$, Lisbon, 1987, pp. 527-546.

7 R. Alonso García, El Juez nacional en la encrucijada europea de los derechos fundamentales, Civitas, Madrid, 2014, p. 152.

8 Para la doctrina española L. MARTín Retortillo BAquer, Vías concurrentes para la protección de los Derechos Humanos, Cizur Menor, Thomson-Civitas, 2006, p. 155.

9 J. García Roca, «El diálogo entre el Tribunal Europeo de Derechos Humanos y los Tribunales constitucionales en la construcción de un orden público europeo», Teoría y realidad constitucional, n. ${ }^{\circ}$ 30, 2012, p. 201. 
sincrónico que viene a poner fin al diálogo diacrónico e indirecto, dilatado en el tiempo, que hasta ahora era el único posible. Con ello se habría alcanzado para algunos el ideal de interacción entre el TEDH y las jurisdicciones nacionales, toda vez que la cuestión prejudicial constituiría la quintaesencia de los instrumentos de diálogo entre tribunales ${ }^{10}$. Para otros, en cambio, la nueva cuestión prejudicial, no sería más que una «falsa buena idea» ${ }^{11}$. Más razonable parece reconocer que aun representando una indudable ventaja para el diálogo, no será tampoco una panacea que haga desaparecer todos los problemas y conflictos ${ }^{12}$.

Se ha dotado por tanto a este mecanismo de consulta de algunas de las características de una cuestión prejudicial, dado que solo podrá activarse en el marco de un proceso concreto en el que resulte aplicable una disposición convencional, lo cual excluye por tanto el ejercicio de un control abstracto. El propio TEDH ha puesto énfasis también en evitar que con este mecanismo se pretenda ejercer su jurisdicción de tutela de los derechos como una jurisdicción de corte casacional revisando los hechos ${ }^{13}$. Precisamente ese carácter cercano, similar en algunos aspectos, a la cuestión prejudicial ante el Tribunal de Justicia de la Unión Europea (TJUE), se ha revelado como uno de los motivos que al día de hoy, señaladamente tras el esperado Dictamen 2/13 sobre la adhesión de la UE al CEDH de 18 de diciembre de 2014, conducen a considerar el Borrador de adhesión incompatible con el Derecho de la UE. La nueva cuestión prejudicial ante el TEDH se percibe en efecto como una amenaza a la incorporación de un better standard en la protección de derechos contenidos en la Carta de Derechos de la UE que, a pesar de incluir el $\mathrm{CEDH}$ como fuente subsidiaria, no está exenta de colisionar con él, como el asunto Melloni ha puesto de manifiesto.

A los supuestos de aplicación de normas de la UE se refiere el Dictamen 2/13 del TJUE de 18 de diciembre de 2014 sobre la adhesión. El propio Dictamen apunta a que «no puede excluirse que una solicitud de opinión consultiva formulada en virtud del Protocolo n. ${ }^{\circ} 16$ por un órgano jurisdiccional nacional pueda desencadenar el procedimiento denominado de intervención previa del Tribunal de Justicia», que se contiene en el propio Proyecto de adhesión y que permite que el TJUE intervenga en los procedimientos ante el TEDH en los que se cuestione el Derecho de la UE, cuando no exista una interpretación del TJUE ${ }^{14}$. Todo parece indicar que el TJUE alberga el temor de que un tribunal nacional de última instancia prefiera acudir al TEDH a través del Protocolo 16 para preguntar sobre la compatibilidad del Derecho de la UE con el CEDH, o que incluso pretenda alegar que la interpretación que haga el TEDH de la carta de Derechos es un acte clair como resultado de la aplicación concordada de los arts. 52.3 y 53 de la CDFUE.

10 F. Benô̂t Rohmer, «Les perspectives de réformes à long terme de la Cour européenne des droits de l'homme: «certiorari» versus renvoi préjudiciel», Revue universelle des droits de l'bomme, vol. 14, núms. 7-8, 2002, p. 314.

11 F. KRENC, «Une nouvelle compétence consultative pour la C.E.D.H.: une fausse bonne idée?», Journal des tribunaux, vol. 29, n. ${ }^{\circ} 6489,2012$, pp. 600-601.

12 J.P. Costa, «La Cour européenne des droits de l'Homme et le dialogue des juges», F. Lichére, L. Potvis-Solis, A. RAYNOUARD, (dirs.); Le dialogue entre juges européens et nationaux: incantation ou réalité?, Bruxelles, Bruylant, 2004, p. 159.

13 Así se recoge en el párrafo 8 del Reflection Paper del TEDH sobre el Borrador de Protocolo 16 (Draft Protocol 16), adoptado por el Pleno el 6 de Mayo de 2013. Vid. M. BreuER, «Wirkungen von Urteilen des EGMR nach 60 Jahren: noch klassisches Völkerrecht oder schon Teil eines „ordre constitutionnel européen«?, A. ZIMMERMANN (ed.), 60 Jahre EMRK - Die Konvention als «living instrument», Berliner Wissenchafts Verlag, 2014, p. 57.

14 Ibid., párrafo 198. 
Comoquiera que sea, se deduce por tanto del citado Dictamen una prohibición de utilizar la cuestión del Protocolo 16 ante el TEDH, siempre que el juez nacional aplique el Derecho de la UE, siendo obligatorio el reenvío prejudicial al TJUE, a no ser que el propio TJUE haya admitido en su jurisprudencia diferentes estándares de protección en los estados miembros ${ }^{15}$.

\section{EL CONTEXTO DE ELABORACIÓN DEL PROTOCOLO 16}

La idea de introducir un procedimiento de consulta al TEDH por parte de la jurisdicción nacional, se remonta en realidad a las propuestas presentadas por el denominado Grupo de Sabios en su Informe de 16 de noviembre de 2006. Posteriormente se incluye formalmente en la Declaración adoptada en la Conferencia de Alto nivel sobre el futuro del TEDH celebrada en Izmir (Turquía) el 27 de Abril de 2011. En efecto, en el punto $\mathrm{D}$ del Plan de Seguimiento incorporado como anexo a la Declaración, se invitaba al Comité de Ministros a reflexionar sobre la posibilidad de introducir este mecanismo de consulta sobre la interpretación y aplicación del Convenio. La propuesta sin embargo no se transforma en una iniciativa de reforma formal hasta la Declaración de Brighton, en la que se invita al Comité de Ministros a redactar un Protocolo facultativo, tarea que se encomienda al Comité directivo para los derechos del hombre. El efecto buscado era el de ayudar a los estados a evitar posibles futuras violaciones del $\mathrm{CEDH}$.

La medida prevista en el Protocolo 16 se inscribe de este modo dentro de la estrategia general que viene tratando de paliar la «galopante inflación» de asuntos pendientes ${ }^{16}$, pero que también se dirige a afianzar el papel subsidiario que corresponde al TEDH. Sobre el primero de los problemas ha sido especialmente la medida del juez único en el juicio de admisión (art. 26), la que, junto a otras como la exigencia de haber sufrido un perjuicio importante (art. 35.3.b), ha tenido un efecto más palpable en la entrada de asuntos al Tribunal, viniendo así a mostrar los efectos beneficiosos de la entrada en vigor, en junio de 2010, del Protocolo 14 y 14 bis $^{17}$. Como ha señalado Jean-Paul Costa, anterior Presidente del Tribunal, cabe definir los resultados como espectaculares a la vista de la inversión de la curva entre asuntos enjuiciados y asuntos entrantes que por primera vez se sitúan por debajo de los primeros ${ }^{18}$. Sin embargo la satisfacción producida por la inversión de tendencia no puede ocultar que todavía el número de asuntos pendientes es elevado y que pasa un largo número de años hasta que pueden ser juzgados a pesar de la prelación de las causas según su urgencia y gravedad, y a pesar también de las medidas cautelares del art. $39 \mathrm{CEDH}$. En cuanto a una mejor aplicación de la subsidiariedad, ha sido abordada desde una perspectiva tanto ascendente como descendente. La primera tiene que ver con el compromiso, plasmado en tres Recomendaciones anteriores del Comité de Ministros, para que los estados parte del Convenio desarrollen las vías

15 De ahí que se postule la prioridad de la cuestión prejudicial ante el TJUE frente a la prejudicial consultiva ante el TEDH. T. BRINGS: «Änderungen der EU-Verträge zugunsten des europäischen Grundrechtsschutzes? Junge Wissenschaft im Öffentlichen Recht», JuWissBlog, Eintrag vom 5. Februar 2015, p. 4.

16 La expresión ha sido retomada de un discurso del entonces presidente del Tribunal, Jean-Paul Costa en el encuentro de San Marino de 2007.

17 El Protocolo 14 bis no ha sido ratificado por España.

18 Los datos se refieren a 2011 y 2012. 
procesales oportunas para garantizar los recursos a nivel interno ${ }^{19}$, verifiquen la compatibilidad de proyectos y disposiciones legales en vigor con las normas del Convenio ${ }^{20}$ y se introduzca éste en la enseñanza universitaria ${ }^{21}$, para de este modo prevenir violaciones de los derechos convencionales. Desde la perspectiva descendente, se pretende en cambio que, en su jurisprudencia, el propio TEDH ponga énfasis en la subsidiariedad que inspira el sistema de protección judicial de los derechos del Convenio. Asimismo, tanto el principio de subsidiariedad como la doctrina del margen de apreciación quedarán incorporados al Preámbulo del Convenio, cuando haya terminado el proceso de ratificación del Protocolo 15, adoptado en Mayo de 2013.

El tipo de cuestión prejudicial consultiva introducida en el Protocolo 16 tiende, al igual que el principio del margen de apreciación, a operar como un instrumento de subsidiariedad, dado que mantiene al juez nacional en su posición natural, de ejercicio del control de convencionalidad primario de actos u omisiones de los poderes públicos nacionales. Ello es tanto más cierto cuanto que será difícil que el juez se aparte de la opinión emitida por el TEDH. Sin embargo, al carecer de efecto vinculante, la interpretación o resolución de las consultas sometidas mediante este mecanismo lo distancia de otras fórmulas similares como la cuestión prejudicial del Tratado de la UE. Deben además tenerse en cuenta las diferencias entre la subsidiariedad de la UE y la del CEDH, puesto que mientras en el primer caso se trata de una subsidiariedad concurrente, en el caso del TEDH se trata de una subsidiariedad de complementariedad, que hace intervenir al TEDH cuando las instituciones nacionales no pueden asegurar una protección efectiva de los derechos garantizados.

Se diría que, con la configuración recibida, la cuestión prejudicial ante el TEDH instaura un mecanismo paralelo y complementario a otros procedimientos que, sin haber sido previstos en la redacción original del Convenio, se introdujeron con posterioridad y que permiten consultar sobre asuntos no contenciosos. El primero en ser introducido, en 1960 (aunque su entrada en vigor solo se produjo en 1970), fue el procedimiento recogido inicialmente en el Protocolo 2 que en la actualidad, tras haberlo incorporado al propio texto del Convenio en 1998 mediante el Protocolo 11, aparece recogido en el art. $47 \mathrm{CEDH}$ con idéntico contenido, y ello a pesar de las voces que recomendaban cambios en su redacción dado su escaso margen de aplicación ${ }^{22}$. Este procedimiento permite al Comité de ministros decidir por mayoría solicitar al Tribunal opiniones de carácter consultivo. Sin embargo, el objeto de este tipo de consultas es enormemente restringido, puesto que el art. 41.3 CEDH efectúa una delimitación en sentido negativo, excluyendo que la consulta pueda recaer sobre el contenido o

$19 \mathrm{R}(2004) 6$.

$20 \mathrm{R}(2004) 5$.

$21 \mathrm{R}(2004) 4$.

22 Así, por ejemplo, Decaux se ha lamentado de que «el Protocolo n. ${ }^{\circ} 11$ se haya limitado a integrar tal cual las disposiciones del Protocolo n. 2 en el texto del Convenio». Indica este autor que «el procedimiento de opiniones consultivas (art. 47 y ss.) es tan cerrado que no se ve en qué hipótesis podría ser puesto en práctica». De ahí que se mostrara partidario de configurar la función consultiva del Tribunal a semejanza de la que existe en el Tribunal Internacional de Justicia o en el sistema interamericano, abriendo el procedimiento consultivo al Secretario General, al Comisario para los derechos del hombre, a la Asamblea parlamentaria e incluso a las instituciones comunitarias a falta de un reenvío prejudicial. Vid. E. Decaux, «Rapport», G. Cohen-Jonathan, C. Pettitit, (éd.); La réforme de la Cour européenne des droits de l'bomme, Bruxelles, Bruylant, 2003, pp. 114 y 115. 
extensión de los derechos y libertades definidos por el CEDH y sus protocolos, ni sobre otras cuestiones que el TEDH o el Comité de ministros hayan tenido que conocer en el marco de un proceso. La consulta debe ceñirse a una «cuestiones jurídicas en torno a la interpretación del CEDH» (art. 1 del Protocolo 2) o, como indicaba la Recomendación 232, de 22 de enero de 1960, «sobre la interpretación de las disposiciones del CEDH si existe una duda de tipo jurídico». Del mismo modo, el art. $48 \mathrm{CEDH}$ puede operar como obstáculo al disponer que el TEDH es quien decide si la cuestión sometida entra dentro de sus competencias. Lo mismo cabe decir del art. 47.2 CEDH, que permite al TEDH declinar su competencia si considera que la cuestión sometida a interpretación puede ser objeto de un posible recurso individual, como ya ocurrió en 2004 con el sometimiento por el Comité de Ministros de una consulta en torno a la coexistencia del $\mathrm{CEDH}$ con el Convenio de derechos del Hombre y libertades fundamentales de la Comunidad de Estados Independientes (CEI).

Esta configuración aparentemente tan estricta es lo que según algunos autores ha provocado que este procedimiento quedase prácticamente inédito, como pone de manifiesto que haya sido utilizado solo en contadas ocasiones en cuarenta años, de las cuales la mayoría de consultas solicitadas ni siquiera han terminado siendo transmitidas al TEDH al no superar la votación por mayoría en el seno del Consejo de Ministros. Sin embargo, en su concepción originaria el procedimiento de consulta resultaba coherente con la lógica de excluir de su ámbito cuestiones que, presentadas como una consulta, podrían esconder un asunto litigioso, lo cual impediría aplicar las garantías propias de un proceso judicial. De hecho, la Comisión jurídica de la Asamblea parlamentaria enumeraba toda una serie de problemas interpretativos susceptibles de ser objeto de este procedimiento de consulta ante el TEDH, entre los que se mencionaba la posibilidad de que los estados parte consultaran sobre la adecuación de proyectos de ley a las disposiciones del Convenio, o también que el Comité de Ministros planteara sus dudas interpretativas en torno a las modalidades de aplicación del art. 32 o del art. 54 (control de la ejecución de las sentencias). Sin embargo, no se ha acudido en la medida de lo esperado a la utilización del procedimiento de consultas, quizás debido a que en buena parte todos los posibles problemas interpretativos que señaló la Comisión jurídica, tuvieron su apropiada respuesta con la puesta en práctica de los procesos ante el TEDH. No obstante, si en cierto modo puede comprenderse que los problemas interpretativos estrechamente ligados a las modalidades procedimentales de aplicación del Convenio se disiparon rápidamente, no cabe decir lo mismo respecto a las consultas previas que los estados podían haber dirigido sobre la adecuación de proyectos de ley a las disposiciones del Convenio. Dicha posibilidad fue conscientemente rechazada debido a razones que el propio TEDH decía entender. Entre los inconvenientes que se atisbaban si se ejerciera un control previo y abstracto de carácter consultivo sobre disposiciones normativas de los estados miembros, se encontraban el que resultaría comprometedor y confuso resolver favorablemente sobre la compatibilidad de un proyecto de ley cuya aplicación o interpretación puede ser, tras su entrada en vigor, objeto de enjuiciamiento en un proceso ante el TEDH en el que se resuelva que ha existido violación del Convenio. Asimismo, para aquellos estados con una legislación similar se verían en una posición delicada. Incluso podría no ser atendido por el Poder legislativo nacional la incompatibilidad declarada tras la consulta, lo cual repercutiría sin duda en la autoridad del TEDH. A todas esas razones se sumaba la de que ni siquiera el Tribunal de Justicia de la Unión Europea (UE), instancia que tiene 
encomendada la uniformidad del Derecho comunitario, ejercía un control sobre las legislaciones internas. Así las cosas, la lánguida existencia determinada por el escaso uso del procedimiento de consultas, condujo a la doctrina a calificar este procedimiento de consulta como un elemento puramente ornamental y por tanto prescindible.

Existe un segundo procedimiento de consulta que puede poner en marcha el Comité de Ministros por mayoría de 2/3, solo que en el marco de la ejecución de las sentencias del TEDH. Este segundo procedimiento de consulta fue incluido en el nuevo art. 46.3 CEDH por el Protocolo 14, que contempla que «cuando el Comité de Ministros considere que la vigilancia de la ejecución de una sentencia definitiva sea entorpecida por una dificultad de interpretación de esta sentencia, puede instar al Tribunal a fin de que se pronuncie sobre esta cuestión de interpretación». Sin embargo, y al igual que en el procedimiento consultivo del Protocolo 2, el mecanismo de consulta sobre la ejecución de sentencias se ha visto en parte inutilizado por instrumentos alternativos que han venido a superponerse. Es el caso de las sentencias "piloto», en parte ideadas como una reivindicación del propio TEDH frente al mecanismo de consulta, que ha sido interpretado como una imposición del Comité de Ministros. Este tipo de sentencias introducen en efecto las medidas generales de reparación que un Estado condenado debe aplicar para cumplir la condena, pretendiendo así evitar cualquier duda interpretativa sobre las modalidades de ejecución de la misma, lo que convierte en prescindible el procedimiento de consulta de dudas sobre la ejecución creado por el Protocolo 14.

\section{NATURALEZA DE LA CUESTIÓN PREJUDICIAL ANTE EL TEDH}

La nueva cuestión prejudicial ante el TEDH, no puede ser considerada estrictamente un reenvío ${ }^{23}$, sino una cuestión incidental de la que está ausente la obligatoriedad. No tendría sentido por ello aplicar una doctrina como la del acto claro, concebida en realidad para exonerar de la obligación de solicitar aclaración, por lo que el tribunal nacional bien podrá fundar el planteamiento de la cuestión ante el TEDH, —incluso existiendo doctrina clara y consolidada del TEDH—, con vistas a solicitar un revirement de la línea jurisprudencial sostenida hasta ese momento ${ }^{24}$. No obstante, no es pacífica esta cuestión, pues la función que pretende cumplir la cuestión prejudicial ante el TEDH es la de abordar cuestiones nuevas o que puedan suscitar un importante número de contenciosos, pero no parece que sea la de intentar hacer reconsiderar una jurisprudencia consolidada ${ }^{25}$. De hecho, el Explanatory Report ${ }^{26}$ hace hincapié en que el órgano de la jurisdicción nacional

23 F. SUDRE, «La subsidiarité, «nouvelle frontière» de la Cour européenne des droits de l'homme. A propos des Protocoles 15 et 16 à la Convention», La Semaine Juridique, (édition générale), n. ${ }^{\circ}$ 42, 2013, p. 1915.

24 R. Contr, «La richiesta di «parere consultivo» alla Corte europea delle Alte Corti introdotto dal Protocollo n. 16 annesso alla CEDU e il rinvio pregiudiziale alla Corte di Giustizia UE. Prove d'orchestra per una nomofilachia europea», Consulta online, 18.05.2014, p. 7.

25 J.P. JACQUÉ, «Le renvoi préjudiciel devant la Cour européenne de droits de l'homme», AA.VV., Comment assurer une plus grande implication des juridictions nationales dans le système de la Convention? Dialogue entre juges 2012, Strasbourg, Cour européenne des droits de l'homme, 2012, p. 22.

26 Documento redactado para explicar el contenido del Protocolo por los expertos del Grupo de Trabajo denominado Drafting Group B on the reform of the Court (GT-GDR-B), encargado de su redacción por el Comité Direc- 
deberá exponer en la formulación de la cuestión prejudicial las razones que justifiquen su necesidad o utilidad. Así ha ocurrido con la primera cuestión planteada ante el TEDH planteada por la Corte de Casación francesa el 5 de octubre de 2018, en la que se exponen las razones por la que sometía a consulta si en aplicación del art. $8 \mathrm{CEDH}$ se excede del margen de apreciación el rechazo de inscripción en el registro de la filiación de una madre de intención en la gestación subrogada por no ser madre biológica, a pesar de que será madre de adopción, cuando al padre biológico y de intención sí se le permite ser inscrito (Arrêt n. ${ }^{\circ} 638$ du 5 octubre 2018 (10-19.053) —Cour de cassation- Assemblée plénière).

Cualquier intento de comparación con la cuestión prejudicial del Derecho de la UE debe ante todo resaltar el diferente contexto en el que opera el Tribunal de Justicia de la Unión Europea (TJUE), así como la diversa naturaleza de sus funciones. Su naturaleza se asemeja a la de un órgano jurisdiccional supremo o superior en los ordenamientos nacionales que ejerce una función ante todo nomofiláctica por la vía del recurso de anulación, lo que le otorga el poder anular disposiciones normativas comunitarias con efectos generales y vinculantes para los tribunales nacionales. Además de ello, el TJUE es un órgano de un sistema jurídico que se desarrolla mediante normas unilaterales. El TEDH por su parte, en cambio, es un órgano jurisdiccional de control de los Estados, cuya función es interpretar un Tratado y que ejerce sus funciones resolviendo normalmente sobre las causas individuales que se le plantean. Su función se agota por ello en resolver sobre las posibles violaciones al Convenio y deducir las eventuales consecuencias de tipo indemnizatorio que eventualmente pudieran derivarse. Ahora bien, la relevancia de sus funciones estriba en que a través de ellas desempeña un control que tiene doble naturaleza. De una parte, en efecto, la función de velar por la conformidad al Convenio controlando toda injerencia por parte de los estados, examinando si ha existido violación de los derechos y libertades individuales, es propia de una jurisdicción de amparo. De otra parte, la función de definir los principios y estándares comunes en materia de derechos para determinar un nivel mínimo de protección supone ejercer una función de naturaleza constitucional, como ya advertía el Grupo de Sabios en su informe ${ }^{27}$. En el primer caso es notorio el carácter subsidiario que acompaña a esta forma de protección jurisdiccional, lo que implica que en todo caso se deben agotar los recursos internos, derivándose de ello una primera y sustancial diferencia respecto al control ejercido por el TJUE.

A pesar del diferente contexto apuntado, el reenvío prejudicial comunitario ha estado presente de un modo u otro en los trabajos del Grupo de Sabios desde su propuesta en su Informe de 2006, en el que se sugería que el procedimiento podría tomar como modelo el establecido en el art. 267 TFUE (anterior art. 234), haciéndose eco de esta manera de lo que durante décadas había venido siendo objeto de debate en foros informales. No obstante, el Grupo de Sabios desechó un trasplante de la cuestión prejudicial comunitaria, pues su naturaleza de preliminar rule y de preliminar reference le confiere, a juicio del Informe, la función de un modelo de control judicial alternativo al que se desarrolla en vía principal, que aumentaría más si cabe la sobrecarga del TEDH. A ello se une la incompatibilidad de la cuestión prejudicial obligatoria y vinculante con la subsidiariedad que exige agotar los

tor de Derechos Humanos.

27 J. MARTin HofFManN -F- KollmaR, «Ein Vorabbefassungsverfahren beim EGMR— das 16. Zusatzprotokoll zur EMRK», Neue Zeitschrift für Verwaltungsrecht, 2014, p. 1269. 
recursos nacionales. De ahí que el Grupo de Sabios desaconsejara su trasplante sin más y se pronunciara a favor de configurar las consultas interpretativas como un mecanismo muy residual y secundario y definir unas condiciones restrictivas para su planteamiento por el juez nacional ${ }^{28}$. El diseño del mecanismo de consulta en el Informe de Sabios recomendaba por tanto no introducir el reenvío prejudicial comunitario, pero sí inspirarse en él ${ }^{29}$. A estos efectos, el borrador del Informe del Grupo de Sabios apuntaba que el sistema de control sobre el que se articula la protección del CEDH, a semejanza del comunitario, se desdobla también en un control concentrado en el TEDH y en el control difuso que corresponde a las jurisdicciones nacionales ${ }^{30}$. Ahora bien, esta coincidencia con la protección de derechos en el seno de la UE desaparece si se tiene en cuenta por un lado el carácter voluntario del planteamiento de la cuestión prejudicial ante el TEDH y por otro sus efectos no vinculantes. Se ha querido preservar de este modo la vía del recurso individual como la única apta tanto para adquirir autoridad de cosa juzgada desplegando efectos vinculantes (art. 46 $\mathrm{CEDH}$ ), así como también para juzgar sobre la incompatibilidad del derecho nacional con el CEDH (art. $1 \mathrm{CEDH})$.

La instauración de la cuestión consultiva ante el TEDH supone adoptar una línea que también se prospecta para el futuro del TJUE, pues, como observa Cartabia, hoy en día la actividad judicial aparece más orientada hacia la interpretación, en el sentido de que las jurisdicciones constitucionales pretenden acomodar los casos y controversias mediante los mecanismos de la interpretación, de modo que una jurisdicción de derechos debe de desenvolver una actividad más cercana al ars interpretandi que al ars decidendi ${ }^{31}$.

Dada la naturaleza de la tutela y del tipo de control que se ejerce en cada uno de los casos, la cuestión consultiva al TEDH no puede ser equiparada en todos sus extremos al reenvío prejudicial de la UE. Efectivamente, en el caso de la cuestión prejudicial comunitaria el juez nacional dispone de un poder de inaplicación del derecho interno ultra vires, incluso cuando lo que está ventilando es una duda interpretativa, debido a que el Derecho de la UE impone su propia primacía con independencia del contenido material de las normas nacionales o del efecto más garantista de la prevalencia de sus normas. Se sigue de ello que no por el hecho de disponer de un estándar mejor en la norma estatal ésta desplace a la norma comunitaria. En cambio, por su parte, el control de convencionalidad pone a disposición del juez un poder de aplicación del better standard, ofreciendo por tanto una alternativa en la norma a aplicar, lo que conlleva que puede darse aplicación al derecho interno frente al derecho convencional. Por ello, un efecto beneficioso que se seguiría de la nueva vía incidental del Protocolo 16 sería el de contribuir a obtener una respuesta interpretativa del TEDH sobre derechos que no hayan sido objeto de ninguna sentencia interpretativa, lo que permitiría al juez nacional inaplicar normas internas incompatibles con el Convenio, como se deduce $a$ contrario de la doctrina sentada en el caso Vermeire c. Belgique, en la que el TEDH entendía que no puede permitir que se suspenda la aplicación de la Convención en espera del resultado de una reforma legislativa ${ }^{32}$, de donde se infiere que el juez nacional estaría obligado a

28 Report of the Wise Persons to the Committee of Ministers, $\$ 79$.

29 CM (2006)88, 10 de Mayo de 2006, § 60.

30 CM (2006)88, 10 de Mayo de 2006, § 28.

31 M. Cartabia, «Europe and Rights: Taking Dialogue Seriously», European Constitutional Law Review, vol. 5, n. $^{\circ} 1,2009$, p. 30.

32 STEDH de 29 de noviembre de 1991, § 26. 
considerar inaplicables normas internas que pudieran revelarse incompatibles con el CEDH cuando ya existe un precedente en la jurisprudencia TEDH sustancialmente similar. Interpretado a contrario el mencionado criterio jurisprudencial, existiendo el mecanismo de consulta previa al TEDH el juez podría inaplicar la norma nacional si de la opinión del TEDH se deriva la violación de las disposiciones convencionales.

Ambas cuestiones prejudiciales, comunitaria y convencional, difieren no obstante en un aspecto esencial que es el del carácter vinculante de la resolución de la cuestión interpretativa. Ello hace pensar que, a diferencia del reenvío comunitario, la cuestión prejudicial convencional no llegará a anular en la práctica, como en ocasiones sucede con el TJUE, el margen de autonomía de que dispone el juez nacional para resolver la litis apartándose de la respuesta recibida, al menos mientras se mantenga su carácter no vinculante, de manera que una respuesta taxativa del TEDH no estará en condiciones de cerrar el espacio de discrecionalidad del juez nacional, que puede llegar a apartarse de la respuesta recibida a su duda interpretativa. Es cierto que la concesión de un margen de discrecionalidad interpretativa parece que debiera ser consustancial a la cooperación que fundamenta la cuestión prejudicial.

Ahora bien, la falta de un efecto vinculante de la respuesta a la cuestión consultiva ante el TEDH, no implica una total irrelevancia jurídica de la interpretación recibida en respuesta a la cuestión. Ante todo, porque lo que existiría es un "vínculo de hecho» ${ }^{33}$ que, si bien no produciría una vinculación directa o inmediata de los tribunales nacionales, crearía en cambio al menos una vinculación mediata o indirecta a la respuesta recibida $^{34}$. Además, la vinculación del juez nacional puede determinarse a partir de otros instrumentos. En concreto, si el juez nacional se aparta de la interpretación que hace el TEDH, puede darse por hecho que la sentencia del caso en cuestión terminará por ser recurrida en Estrasburgo por una de las partes y que finalice en una condena por violación de alguno de los derechos del Convenio ${ }^{35}$. Ello presupone que el TEDH, como expresamente ha reconocido, se va a sentir autovinculado por sus opiniones interpretativas ${ }^{36}$, de manera que declarará infundados los motivos de un recurso individual posterior al proceso judicial nacional en el que se ha seguido la interpretación suministrada en respuesta a la cuestión prejudicial ${ }^{37}$. De ahí que se haya subrayado el efecto devaluador que la opinión del TEDH tendrá sobre el juicio ante la jurisdicción nacional ${ }^{38}$. Cuestión distinta es que el TEDH pueda someter a escrutinio la aplicación que haya hecho el tribunal nacional de la opinión consultiva que resuelve la cuestión prejudicial, en semejanza con lo que ocurre cuando el TEDH debe pronunciarse sobre asuntos anteriormente sometidos a su jurisdicción contenciosa y resueltos mediante sentencia. En tales casos el TEDH suele

33 G. Centamore, B. Agostini, «Protocollo XVI alla Convenzione europea dei diritti umani: Osservazioni generali», Diritto Penale Contemporaneo, 14-06.2014, p. 12.

34 G. Asta, «Il Protocollo 16 alla CEDU: Chiave di volta del sistema europeo di tutela dei diritti umani?», Comunità Internazionale, vol. 68, n. ${ }^{\circ} 4,2013$, p. 784.

35 J. Gerards, «Advisory Opinions, Preliminary Rulings and the New Protocol No. 16 to the European Convention of Human Rights: A Comparative and Critical Appraisal», Maastricht Journal of European and Comparative Law, vol. 21, n. ${ }^{\circ}$ 4, 2014, p. 636.

36 Reflection Paper, § 44 .

37 Indudablemente ello tiene como ventaja la posibilidad de que las opiniones consultivas del TEDH eviten una avalancha de recursos individuales. Andreas Zimmermann (ed.), 60 Jahre EMRK - Die Konvention als ,living instrument «», Berliner Wissenchafts Verlag, 2014, p.153.

38 Centamore - Agostini, «Protocollo XVI alla Convenzione europea dei diritti umani...», op. cit., p. 12. 
revisar la eficacia y suficiencia de las medidas de ejecución para reparar la violación del Convenio, y si bien lo resuelto en una opinión consultiva no puede equipararse a lo decidido mediante sentencia, no es impensable que se aplique un examen sobre su correcta interpretación o aplicación por parte de la jurisdicción nacional ${ }^{39}$.

No se pueden, por otra parte, equiparar tampoco los dos tipos de cuestiones prejudiciales que pueden plantearse ante el TJUE en virtud del art. 267 TFUE desde el punto de vista de su objeto, pues mientras que en el caso de la cuestión sobre el control de validez se trata de un mecanismo de depuración de las normas de las instituciones europeas, la cuestión de interpretación en cambio no persigue la misma función, sino que su naturaleza es la de un mecanismo de cooperación judicial que pretende garantizar una interpretación y aplicación uniforme del Derecho de la UE, que queda sustraída al juez ordinario para asegurar el monopolio del TJUE, de tal modo que su planteamiento es preceptivo, integra las garantías del proceso debido y su incumplimiento supone un exceso de jurisdicción. Así pues, existe una cierta semejanza entre la cuestión prejudicial comunitaria de interpretación y la cuestión prejudicial del Protocolo n. ${ }^{\circ} 16$ del Convenio en cuanto que ambas se dirigen a armonizar la interpretación del Derecho europeo (de la UE y del CEDH) en su aplicación a hechos o normas nacionales. Donde esa similitud se rompe es tanto en lo concerniente al nivel de concreción de la pregunta, así como en lo que se refiere a la funcionalidad de la interpretación recibida como respuesta a la cuestión. Respecto a lo primero, la cuestión prejudicial convencional solo puede versar sobre cuestiones de principio ${ }^{40}$. Ese alto grado de indeterminación no queda del todo despejado en las aportaciones del Comité de Ministros y del propio TEDH al borrador del Protocolo 16. Así, en el art. 1 (2) del Explanatory Report se excluye que el procedimiento de consulta pueda estar dirigido, por ejemplo, a permitir un control abstracto de la legislación que no deba de aplicarse al caso pendiente». En cambio, el TEDH reconoce que los asuntos sobre cuestiones de principio sobre los que deba emitir avis consultatifs podrían englobar aquellos que versen sobre «la compatibilidad con el Convenio de una ley, una regla o una interpretación constante de una ley por un tribunal» ${ }^{41}$, lo que supone instaurar un control concreto sobre su convencionalidad, que estará limitado, — como el propio Tribunal explica-, «a las cuestiones que se planteen en las causas contenciosas en las que estén en juego derechos individuales, sin llegar por tanto a ejercer un control abstracto de las leyes» ${ }^{42}$.

La clarificación de cuáles sean este tipo de cuestiones de principio es preciso ir a buscarla en el Explanatory Report del Protocolo $11^{43}$, donde se concreta el sentido de la expresión 'importantes cuestiones de interpretación y aplicación' del art. $43 \mathrm{CEDH}$. Entre las cuestiones de especial importancia sobre interpretación dicho Informe incluye las planteadas respecto a algún punto sobre el que el Tribunal no haya tenido oportunidad de

39 V. Petralia, «A proposito del futuro della Corte europea dei diritti dell'uomo. Prime note sul .n. XVI alla Convenzione europea dei diritti dell'uomo», I quaderni europei, n. ${ }^{\circ}$ 57, 2013, p. 18.

40 En la propuesta de expertos danesa y holandesa se pretendía en cambio circunscribir la cuestión a supuestos en que existieran problemas sistémicos o estructurales, lo cual estrechaba aún más su ámbito.

41 Reflection Paper, $\$ 29$.

42 Reflection Paper, $\$ 29$.

43 E. Nalin, «I Protocolli n. 15 e 16 alla Convenzione europea dei diritti dell'uomo», MARTINO, P. (a cura di); I giudici di common law e la (cross)fertilization: i casi di Stati Uniti d'America, Canada, Unione Indiana e Regno Unito, Santarcangelo di Romagna, Maggioli Editore, 2014, p. 141. 
pronunciarse, que sea o bien capaz de influenciar la jurisprudencia futura del Tribunal, o susceptible de imprimir un giro a la jurisprudencia anterior ( $§ 100)$. Respecto a las cuestiones importantes o trascendentes sobre la aplicación del Convenio, el Explanatory Report sobre el Protocolo 11 entiende por tales las que puedan producir una modificación sustancial en el ordenamiento interno o en la praxis administrativa de un Estado, sin necesidad de que planteen graves cuestiones interpretativas ( $\$ 101)$, lo cual supone admitir implícitamente las cuestiones sobre problemas sistémicos o estructurales. No obstante, el propio Grupo de redacción del Protocolo, advierte que a pesar de las similitudes entre el procedimiento de revisión de recursos a la Gran Sala y el de las opiniones consultivas mediante el planteamiento de la nueva cuestión, no puede establecerse una total identidad en la aplicación de los criterios de admisión de las cuestiones consultivas, pues ambos procedimientos difieren en cuanto a los propósitos que persiguen ${ }^{44}$.

Otro de los aspectos que alejan la cuestión previa consultiva ante el TEDH de la cuestión prejudicial comunitaria es su carácter subsidiario, lo cual ha sido determinante para no dotar de carácter vinculante a la respuesta emitida por el TEDH. Precisamente una de las dificultades señaladas en debates académicos y sondeos previos al estudio de las reformas del TEDH ha sido la de que un recurso prejudicial sería incompatible con el principio de subsidiariedad y con el tipo de control que ejerce el Tribunal ${ }^{45}$.

\section{EL DIÁLOGO ENTRE TRIBUNALES Y LA TRIPLE PREJUDICIALIDAD EN LA JURISDICCIÓN CONSTITUCIONAL}

\section{Tipos de conflictos con entre jurisdicción convencional y constitucional}

De prosperar la ratificación del Protocolo 16, la que podemos denominar cuestión prejudicial convencional, vendría a incrementar la complejidad que ya existe en aquellos ordenamientos de estados de la UE en los que existe la cuestión previa de constitucionalidad. Ilustrativo es el caso francés y en general aquellos sistemas en los que control de constitucionalidad y control de convencionalidad han venido siendo ejercidos por órganos separados.

La posibilidad de conflictos entre jurisdicciones europeas y jurisdicción ordinaria y constitucional es más elevada en estos sistemas, siendo variadas las situaciones o tipos de conflictos que se pueden presentar. En todo caso, forzoso es admitir que la fuente de este tipo de situaciones proviene del control al que de manera indirecta se ve abocado el TEDH sobre la legislación nacional, e incluso sobre disposiciones constitucionales, cuando la injerencia en un derecho se debe a la propia existencia de una ley o bien a su aplicación. Y, aunque no exista identidad de causas jurídicas, está fuera de duda que existe una concurrencia de jurisdicciones propiciada por normas sobre derechos materialmente similares o idénticas. Si bien el TEDH ha rechazado la posibilidad de ejercer el

44 Vid. Draft Explanatory report to Protocol $n .^{\circ} 16$, Strasbourg, 30 November 2012, CDDH(2012)R76 Addendum VI, §9.

45 C. Pettiti, «La position des avocats français sur la réforme de la Cour européenne des droits de l'homme», Cohen-Jonathan, G. - Pettiti, C. (éd.); La réforme de la Cour européenne des droits de l'bomme, Bruxelles, Bruylant, 2003 , p. 105. 
control de un acto legislativo in abstracto, entiende en cambio que puede llevar a cabo un control in concreto, y ello en la medida que el carácter declarativo de su decisión no afecta a la validez o eficacia de la regla de derecho interno enjuiciada. Aunque el control de la norma legal quede así justificado, por desplegar efectos aparentemente solo sobre el caso concreto, en realidad su alcance va más allá del caso enjuiciado, por cuanto a consecuencia de la inconvencionalidad con origen en la ley, la obligación que deriva para el Estado parte del art. $46 \mathrm{CEDH}$, de cumplimiento de lo dispuesto en la sentencia del caso individual, desborda necesariamente el caso decidido, a pesar de que en principio debiera limitar su alcance a la sanción intuitu personnae de la violación de un derecho subjetivo. Sin embargo es manifiesto que lo supera, pasando a tener alcance general. En definitiva, el cumplimiento estatal exigirá la nulidad o derogación de la ley inconvencional, sin que ello comporte por el momento la existencia de un recurso nacional de inconvencionalidad de las leyes. Junto a ello, y sin necesidad de ejercer un control de este tipo sobre leyes nacionales, la autoridad de cosa interpretada (res interpretata) extiende la interpretación sobre la convencionalidad de otras legislaciones a la del resto de países. Todo ello hace asumir al TEDH una función muy próxima a la de un Tribunal Constitucional ${ }^{46}$, lo que en la práctica significa que el juez o tribunal de la jurisdicción ordinaria parece verse atrapado entre dos fuegos, pues deberá ofrecer una interpretación conforme disputada por dos órganos que reclaman para sí ser la última instancia y, lo que es más, que defienden el carácter autónomo de la respectiva interpretación ${ }^{47}$. Ello naturalmente comporta un grado de complejidad y de potencial conflicto que debe ser soportado por el juez ordinario. Parece por ello conveniente distinguir cuáles serían los distintos tipos de situaciones en las que el juez ordinario parece forzado a optar entre interpretaciones divergentes de la ley.

Un primer tipo de conflicto sería aquel en el que una ley ha sido juzgada por el TEDH supuestamente conforme al $\mathrm{CEDH}$, pero posteriormente ha sido declarada inconstitucional. Un segundo tipo de conflicto sería aquel en que la declaración de inconstitucionalidad ha precedido a un recurso ante el TEDH y éste considerara la pérdida de vigencia de una ley ocasionada por tal declaración como vulneradora de algún derecho convencional. Debe precisarse que con la actual doctrina del TEDH sobre la necesidad de una base legal para admitir una injerencia en los derechos, la inconstitucionalidad de una ley (aun sin efecto retroactivo) privaría de base legal a la decisión que ha podido motivar la injerencia (Baczkowski y otros c. Polonia) ${ }^{48}$. Además de ello, toda declaración de inconstitucionalidad suele producirse por lo común como resultado de una interpretación favorable a los derechos fundamentales. Supuesto distinto, el tercero, es el

46 G. Cohen-Jonathan, «La fonction quasi constitutionnelle de la Cour européenne des droits de l'homme», Renouveau du droit constitutionnel. Mélanges en l'honneur de Louis Favoreu, Paris, Dalloz, 2007, p.1129. No quiere decir ello que se pueda hablar todavía con todo rigor de una jurisdicción constitucional transnacional, a falta de herramientas como la fuerza anulatoria de normas, ni revocatoria de sentencias, ni de retroacción de actuaciones o procedimientos, o a falta de medidas de restablecimiento de un derecho en su integridad. Cfr J. GARCía Roca «La interpretación constitucional de una declaración internacional, el Convenio europeo de derechos humanos y bases para una globalización de los derechos», Revista Europea de Derechos Fundamentales, n. ${ }^{\circ}$ 6, 2005 , p. 42.

47 E. Fosssas ESPALADER, «Cosa interpretada' en derechos fundamentales: jurisprudencia del TEDH y la jurisprudencia constitucional», RVAP, n. ${ }^{\circ} 82$ (II), 2008, p.169.

48 L. GARLICKI, «Contrôle de constitutionnalité et contrôle de conventionalité. Sur le dialogue des juges», en AA.VV. La conscience des droits. Mélanges en l'honneur de Jean-Paul Costa, Paris, Dalloz, 2011, p. 276. 
de la ley declarada constitucional pero posteriormente declarada contraria al CEDH por el Tribunal de Estrasburgo. Dado que en numerosos países existen diferentes vías de recursos constitucionales, es lógico que un asunto haya sido ya decidido por la jurisdicción constitucional nacional antes de ser sometido al TEDH. En este supuesto concreto, en el que la ley ha sido declarada constitucional, a diferencia de las declaraciones de inconstitucionalidad, es donde puede tener particular relevancia la existencia de un control separado de convencionalidad y de constitucionalidad, puesto que en aquellos sistemas en los que la propia jurisdicción constitucional asume también el control de convencionalidad, el esfuerzo por realizar una interpretación conforme al Convenio puede en cierta medida mitigar posibles conflictos. Sin embargo, cuando ambos controles se encuentran separados, el riesgo de un potencial conflicto se acrecienta. En efecto, llegado el caso, el juez ordinario, que es a su vez en estos sistemas juez de convencionalidad de las leyes, tendrá que decidir inaplicar una ley contraria al Convenio cuando así resulta de una interpretación conforme a la luz de la jurisprudencia del TEDH y ello aun cuando en un proceso previo haya sido declarada constitucional. Menos dudas caben, en tercer lugar, si la inconvencionalidad de la ley se desprende de una sentencia del TEDH, siendo en este caso su inaplicación un estricto cumplimiento de la sentencia.

Puede asimismo darse el supuesto, _el cuarto_- de que la constitucionalidad de la ley haya de presumirse en ausencia de declaración expresa de la jurisdicción constitucional, en cuyo caso lo habitual será que los derechos invocados no solo sean los constitucionales sino también los convencionales. En tal circunstancia, países como Francia $^{49}$ o Bélgica ${ }^{50}$ mediante ley han impuesto la obligación al juez ordinario de plantear la cuestión previa de inconstitucionalidad, que goza además de prelación sobre el examen de la compatibilidad con el derecho denominado convencional que el juez ordinario debe llevar a cabo y que comprende todas las obligaciones derivadas del derecho supranacional, incluidas por tanto las exigidas por el Derecho de la UE y las disposiciones del CEDH. El mecanismo introducido para resolver estos casos de doble prejudicialidad no supone sin embargo imponer la concentración de ambos controles en la jurisdicción constitucional. Consecuencia de ello es que el juez ordinario sigue siendo el órgano competente llamado a resolver sobre la convencionalidad de las leyes.

Cabe entonces interrogarse sobre si la prioridad de la cuestión prejudicial de constitucionalidad puede prejuzgar todo examen de convencionalidad del juez cuando el vicio de inconstitucionalidad consista en la vulneración de una disposición del Derecho supranacional, debido a que toda decisión de la jurisdicción constitucional vincula a todos los jueces y además no es impugnable ${ }^{51}$. Como es sabido, este mismo problema se ha planteado ya al poco de aprobarse la referida norma legal en Francia, a raíz de una cuestión prejudicial planteada por la Cour de Cassation ante el TJUE. Dicha cuestión dio lugar no solo al pronunciamiento del $\mathrm{TJUE}^{52}$, sino también al posicionamiento del Conseil

49 En virtud de la ley orgánica 2009-1523 de 10 de diciembre, que modifica los arts. 23-2 (párrafo 5. ${ }^{\circ}$ y el art. 23-5 (párrafo 2) de la ordenanza de 7 de noviembre de 1958.

50 Loi 12 juillet 2009 modifiant l'article 26 de la loi spéciale du 6 janvier 1989 sur la Cour d'arbitrage.

51 Este fundamento de orden institucional para una priorización de la cuestión de inconstitucionalidad es del todo suscribible en el caso español. P. CRUZ VILLALÓN - J.L. REQUEJO PAGÉS, «La relación entre la cuestión prejudicial y la cuestión de inconstitucionalidad», RDCE, n. ${ }^{\circ} 50,2015$, p. 186.

52 STJUE de 22 de junio de 2010. 
Constitutionnel ${ }^{53}$ y del Conseil d'État ${ }^{54}$, dando pie a un interesante diálogo de tribunales. El riesgo de una preclusión del control de convencionalidad que corresponde realizar al juez ordinario, provocado por el envío de una cuestión de constitucionalidad parte en realidad de una falsa premisa, puesto que el control de convencionalidad no queda subsumido en el control de constitucionalidad de la ley. La razón es que si bien el art. 88-1 de la Constitución francesa $(\mathrm{CF})$ puede ser visto como el fundamento constitucional del Derecho de la UE y por consiguiente el sustento para su primacía, debe rechazarse la lectura del mencionado precepto como una subordinación de la constitucionalidad de las leyes al respeto del Derecho de la UE, pues éste gozaría en realidad de la primacía reconocida al Derecho internacional en general por el art. 55 CF. Es cierto sin embargo que tal conclusión no se aplica del todo a las leyes que trasponen las directivas, que sí tienen su fundamento en el art. 88-1 CF y que por esta razón se encuentran sometidas al control de constitucionalidad. Por lo tanto, en palabras del propio Conseil Constitutionnel, la autoridad que dimana de sus decisiones «no limita la competencia de las jurisdicciones administrativas y ordinarias para hacer prevalecer» los compromisos internacionales «sobre una disposición legislativa incompatible con ellos, incluso cuando esta última ha sido declarada conforme a la Constitución»" De ahí resulta que el efecto de cosa juzgada de sus decisiones se impone solo a los motivos de impugnación sobre los que el juez constitucional tiene competencia, por lo que todo lo que exceda la compatibilidad con la Constitución y se refiera a una posible incompatibilidad con el derecho convencional, queda excluido por definición del control de constitucionalidad. Ello implica que el juez ordinario puede ejercer el control de convencionalidad sobre una ley declarada constitucional, bien sea inaplicándola, bien sea planteando la cuestión prejudicial en este caso ante el TJUE. El Conseil Constitutionnel admite por tanto que el juez ordinario pueda plantear la cuestión prejudicial con posterioridad a la transmisión de la cuestión prioritaria de constitucionalidad, e incluso que pueda hacerlo de forma simultánea.

El TJUE no ha compartido del todo este planteamiento y ya ha reiterado con posterioridad en Melki y Abdeli que, en virtud del art. 267 TFUE, el derecho nacional debe permitir al juez ordinario presentar una cuestión prejudicial comunitaria no solo en el mismo momento de proceder a transmitir una cuestión prioritaria de constitucionalidad, o después de ésta, sino también con carácter previo (FF.JJ. 54-56). Debe resaltarse no obstante que este criterio interpretativo del TJUE no se refiere a los casos en que el juez nacional aprecie una contradicción entre norma interna y el Derecho de la UE, pues en tal supuesto no se puede poner en discusión el deber del juez de inaplicar la ley interna, dado que lo contrario vulneraría el propio Derecho de la $U^{56}$. Donde se ha planteado el problema de la prioridad de la cuestión de constitucionalidad respecto a la comunitaria ha sido en el supuesto de una ley de trasposición de una directiva cuya validez respecto al Derecho de la UE se discute, extremo que constituye un prius respecto a la constitucio-

53 En la decisión de 12 de mayo de 2010, (Jeux en ligne).

54 Sentencia Rujovic, de 14 de mayo de 2010 que apoya en lo sustancial las tesis de la Cour de Cassation.

55 Considerando 13

56 Tampoco se puede imponer al juez plantear la cuestión prejudicial como una obligación, a modo de paso previo antes de proceder a dejar sin aplicación una norma interna por no permitir el ordenamiento nacional que sus jueces puedan se abstengan de aplicar disposiciones internas que consideren inconstitucionales sin haber sido declaradas previamente como tales por el Tribunal Constitucional. Así lo ha entendido el TJUE en el asunto Kükükdeveci, STJUE de 19 de enero de 2010 (C-555/07). 
nalidad de la ley interna de trasposición, pues una eventual invalidez de la directiva puede acabar dejando sin objeto el control de constitucionalidad. Esto implica que aunque el TJUE no descarta que se puedan simultanear, la propia naturaleza del Derecho de la UE impide supeditar o condicionar el planteamiento de la cuestión prejudicial comunitaria al resultado de una cuestión de inconstitucionalidad ${ }^{57}$. Por esta razón, la resolución de la cuestión prejudicial comunitaria deberá preceder la resolución de la cuestión de inconstitucionalidad, aun cuando ambas hayan sido planteadas de manera simultánea ${ }^{58}$. Así pues, y como primera consecuencia de esta jurisprudencia, el TJUE despoja de carácter prioritario a la cuestión de constitucionalidad. En segundo lugar, se debe preservar el poder del juez de inaplicar una ley incompatible con el Derecho de la UE, antes y después de la tramitación de una cuestión previa de constitucionalidad. En tercer lugar, discrepa el TJUE sobre la posibilidad de efectuar un control prioritario sobre la constitucionalidad de las leyes de trasposición de directivas siempre y cuando éstas contengan disposiciones imperativas. Por último, el TJUE impone además la obligación a las jurisdicciones supremas de proceder al reenvío prejudicial si los motivos de inconstitucionalidad tienen su equivalente en el derecho originario de la Unión.

Trasladando esta doctrina del TJUE al terreno de la cuestión prejudicial ante el TEDH, parece oportuno referirse a su conveniencia o pertinencia para establecer una prioridad de cuestiones prejudiciales en aquellos sistemas jurídicos en los que existe un control de convencionalidad concentrado en la jurisdicción constitucional.

La concentración de ambos controles en la jurisdicción constitucional se debe a una suma de factores que entran en juego y que van desde el alineamiento con las teorías dualistas de las relaciones entre Derecho interno y Derecho internacional, hasta el rango del Convenio, al que se considera norma interpuesta. Atendiendo a dichos factores, cabe sistematizar el papel de la jurisdicción constitucional en el ejercicio del control de convencionalidad a grandes rasgos en torno a tres modelos. En un primer modelo, que podemos denominar concentrado, la intervención de la jurisdicción constitucional puede venir exigida cada vez que el juez ordinario detecte una contradicción insanable entre norma interna y norma convencional, estando entonces obligado a plantear la cuestión de inconstitucionalidad (Italia). Resulta de ahí que la inconvencionalidad de una norma interna viene reconducida a un incidente de inconstitucionalidad de la misma que puede acabar con su anulación. Ello comporta que, aun siendo el CEDH norma infraconstitucional incorporada mediante ley, resulta por sus características materiales idónea para integrar el parámetro de constitucionalidad de la ley nacional. Dicha consideración como norma paramétrica tendrá lugar siempre y cuando las disposiciones convencionales no entren en conflicto con la propia Constitución, pues en tal caso, o bien se anula la ley de adopción del Tratado en la parte afectada, o bien se la considera inidónea para formar parte del parámetro de enjuiciamiento, provocando entonces una inaplicación de la norma convencional en el juicio de inconstitucionalidad solo para el caso concreto.

57 J.L. Requejo Pagés, «Derecho de la Unión e imposición nacional sobre la utilización de combustible nuclear para la producción comercial de energía eléctrica (Sentencia del Tribunal de Justicia de 4 de junio de 2015, Kernkraftwerke Lippe-Ems)», Actualidad Administrativa, n. ${ }^{\circ}$ 11, Sección Europa, Noviembre 2015, Editorial La Ley, 2015, p. 11.

58 R. Alonso García, El Juez nacional en la encrucijada europea de los derechos fundamentales, Civitas, Madrid, 2014, p. 148. 
En un segundo modelo, que podemos denominar compartido, tanto la jurisdicción constitucional como los jueces ordinarios ejercen directa o indirectamente el control de convencionalidad. Por ejemplo, como sucede en Alemania, la jurisdicción constitucional lleva a cabo un control de constitucionalidad de la aplicación e interpretación del CEDH por el juez ordinario si al desconocer o no tener en cuenta la jurisprudencia del TEDH se ha producido un menoscabo en la protección de un derecho fundamental del texto constitucional $^{59}$. En este caso el Tribunal Constitucional se erige en garante de la aplicación del CEDH sin ser estrictamente éste un parámetro de constitucionalidad. En Alemania el CEDH tiene rango de ley ordinaria, pero el TC ejerce un control de conformidad con las disposiciones del CEDH cuando el grado de protección de las normas de valor constitucional sea inferior. Quiere decirse con ello que los recursos individuales no pueden invocar la violación de las disposiciones del $\mathrm{CEDH}^{60}$. Ahora bien, el rango formal del $\mathrm{CEDH}$ no ha impedido reconocer lo que el TC denomina Völkerrechtsfreundlichkeit hacia el CEDH, lo que se traduce en una eficacia interpretativa de sus disposiciones y de la jurisprudencia del TEDH. Se trata por tanto de sistemas en los que, como en Austria o Alemania, no existe un monopolio del control de convencionalidad en la jurisdicción constitucional pero ésta lo integra en el enjuiciamiento de los recursos individuales directos por violación de derechos constitucionales gracias sobre todo al valor interpretativo de la jurisprudencia del TEDH. En Austria el TC no ejerce un control de constitucionalidad de los tratados, que recae en la jurisdicción ordinaria, pero las normas de origen internacional tienen valor constitucional, de modo que tienen aplicación directa en los recursos individuales contra actos administrativos (art. 144 Const.).

Un tercer modelo, que cabe identificar como difuso o separado, sería aquel en el que los jueces ordinarios ejercen con exclusividad el control de convencionalidad de manera separada a un control de constitucionalidad concentrado (caso de Francia) ${ }^{61}$ o en ausencia de una jurisdicción constitucional. Este último sería el caso de Holanda. En el primer caso, el art. 94 Const. dispone que las disposiciones legales no se aplicarán si entran en conflicto con disposiciones de tratados o resoluciones de instituciones internacionales que vinculen a todos, mientras que en el caso holandés, el art. 120 del texto constitucional prohíbe el control de constitucionalidad de leyes y tratados por los jueces, por lo que en ausencia de jurisdicción especializada, el Tribunal Supremo no puede enjuiciar la constitucionalidad de las leyes. Cabría incluso adscribir España a este tercer modelo, especialmente tras la Ley 25/2014 de Tratados y otros Acuerdos Internacionales.

Puesto que la posibilidad de plantear cuestiones prejudiciales al TEDH aparece en el Protocolo n. ${ }^{\circ} 16$ reservada a altos tribunales, en el modelo de control de convencionalidad concentrado dicha facultad quedaría por tanto circunscrita entre otras a la jurisdicción constitucional. Se viene de este modo a reforzar uno de los argumentos para la concentración del control de convencionalidad que venía defendiendo, en ausencia de un mecanismo prejudicial ante el TEDH, el no dejar en manos del juez ordinario la manipulación

59 Se dice en la Sentencia de 14 de octubre de 2004 (\$ 30): «Verstoß gegen das in seinem Schutzbereich berührte Grundrecht».

60 C. Tomuschat, «The Effects of the Judgments of the European Court of Human Rights According to the German Constitutional Court», German Law Journal, Vol. 11, n. ${ }^{\circ}$ 5, 2010 , p. 518.

61 El propio Conseil Constitutionnel francés ha puntualizado que aunque la ley de ratificación del Protocolo 16 le faculta a plantear la cuestión previa del Protocolo 16, ello no implica que en el ejercicio del control de constitucionalidad en base a los arts. 61 y 61-1 CF, pueda añadir al mismo el control de convencionalidad. 
interpretativa de las normas convencionales. Aun siendo cierto que la inexistencia de un reenvío prejudicial del juez inferior al TEDH puede seguir siendo visto como un argumento para salvaguardar valores irrenunciables como la seguridad jurídica, no es menos cierto que detrás de la prohibición de inaplicación de la norma interna que contradiga el $\mathrm{CEDH}$, está la posibilidad de reconocimiento a los jueces inferiores del ejercicio de un control difuso sobre las leyes cuando entren en conflicto con disposiciones convencionales, lo cual para algunos ordenamientos supone introducir un elemento más propio del common law, en el que el juez se guía por el precedente ${ }^{62}$. El limitadísimo papel que corresponde en estos sistemas al juez ordinario contrasta con el que en circunstancias parecidas tiene el juez ordinario inferior en el ámbito de la cuestión prejudicial ante el TJUE, ya que mediante el planteamiento de ésta, la UE ha podido atraer a las altas jurisdicciones hacia el Derecho europeo.

Uno de los riesgos más patentes que pueden darse en el modelo de control de convencionalidad concentrado es la «domesticación» de las exigencias del control de convencionalidad si se produce una identificación más o menos consciente de los derechos convencionales con los derechos constitucionalizados. En efecto, cabe que el reenvío del juez ordinario a la jurisdicción constitucional sea presentado como una cuestión que afecta a la constitucionalidad de la propia disposición convencional y no como una cuestión que afecta a la convencionalidad de la norma interna. De llegar a entrar en funcionamiento el Protocolo n. ${ }^{\circ} 16$, incluso puede llegar a ocurrir que bajo el ejercicio de un control de constitucionalidad y convencionalidad concentrados, se produzca una «doble prejudicialidad invertida», ya que si se admite que el reenvío prejudicial del juez ordinario al TEDH debe preceder al reenvío a la jurisdicción constitucional, podría llevar a ésta después de la respuesta del Tribunal de Estrasburgo, a obligar a someter al control de constitucionalidad el propio Tratado que establece el CEDH, mediante la impugnación de la ley por el que se adoptó, solución adoptada en los sistemas dualistas como el italiano. De ahí se desprende que en estos sistemas cabrá siempre un control de constitucionalidad del $\mathrm{CEDH}^{63}$, pero no a la inversa (un control de convencionalidad de la Constitución), pues la jurisdicción constitucional, aun cuando acepte llevar a cabo una interpretación conforme de la Constitución al CEDH, que le pueda llevar a una convencionalización de sus derechos, siempre encontrará como límite la supremacía de ésta ${ }^{64}$.

Por tanto, en los sistemas dualistas de recepción de los tratados, en caso de no hallar el juez nacional una interpretación conforme, no se impone la inaplicación de la norma interna, sino que en todo caso se propicia el planteamiento de una cuestión de inconstitucionalidad, dando lugar así a una doble interpretación conforme. De esta manera, la jurisdicción constitucional, para superar la interpretación constitucional no conforme de los enunciados del Convenio (interpretados a la luz de la jurisprudencia del TEDH), acaba operando una interpretación convencionalmente conforme, lo que origina una hipóstasis de ambos tipos de control o, si se prefiere, una duplex interpretatio, que conduce a la jurisdicción constitucional a

62 Se sostiene desde esta perspectiva que el juez ordinario inferior no se encuentra vinculado obligatoriamente a la interpretación del TEDH, dado que no existe un mecanismo procedimental en tal sentido en las disposiciones del Convenio. Si existe algún tipo de vinculación con la jurisprudencia del TEDH es solo imperio rationis.

63 En la sentencia de la Corte costituzionale n. 311 de 2009, se señala que aunque le está impedido controlar la interpretación del Convenio europeo realizada por el Tribunal de Estrasburgo, pues tal función ha sido atribuida por nuestro país sin poner reservas, pero a la Corte constitucional compete, esto sí, verificar si la norma del CEDH, en la interpretación del Tribunal europeo, no entre en conflicto con otras normas de nuestra Constitución» (párr 6).

64 L. Garlicki, «Contrôle de constitutionnalité et contrôle de conventionalité... », op. cit., p. 280. 
rechazar sustituir su interpretación del Convenio por la del TEDH. Es en este tipo de situaciones donde más se evidenciaba la falta de un mecanismo similar a la cuestión prejudicial comunitaria, algo a lo que ya se venía refiriendo la doctrina desde tiempo atrás. Así pues, si de una parte es cierto que en ausencia de un mecanismo de comunicación del juez nacional con el TEDH, ha tenido lugar una rigidificación en las relaciones entre el TEDH y las jurisdicciones nacionales, también es cierto que en contrapartida la subsidiariedad ha tenido en un gran número de ocasiones un «efecto rebote».

De hecho, si algo diferencia al juez nacional en su veste de juez convencional respecto a su papel como juez comunitario, es que no contaba hasta ahora con un procedimiento para zanjar el dilema de tener que respetar obligaciones contradictorias, de modo que, muy al contrario de lo que ocurre en el ordenamiento de la UE, no disponía de un mecanismo de comunicación directa con el juez internacional. Hasta ahora por tanto, lo característico del TEDH es que no se dirigía al juez interno, sino solo al Estado del que forma parte el juez, quien sin embargo se debate entre la fidelidad a las normas estatales que delimitan su competencia y la posibilidad de hacer incurrir a su Estado en responsabilidad internacional. En que esa comunicación directa con el juez no se haya contemplado, ha pesado sin duda el que no exista un monismo en todos los estados a la hora de incorporar el Convenio en su ordenamiento interno. De ahí que el TEDH no haya exigido estrictamente su aplicación directa, dado que el carácter finalista del CEDH impone tan solo la consecución de un resultado. Ello implica que, a pesar de que la regla del agotamiento de los recursos del ordenamiento interno manifieste la inequívoca vocación de los enunciados del Convenio a su eficacia y aplicabilidad directa, el TEDH se ha cuidado de precisar que tal obligación solo existe dentro del límite que el orden competencial interno señala al juez nacional. De este modo, en los estados dualistas, el impedimento que excluye una aplicación directa del CEDH por el juez nacional evita que éste pueda inaplicar una ley interna contraria, pues viene obligado solo a realizar una interpretación conforme al «derecho viviente convencional» contenido en las soluciones del TEDH a cuestiones de tipo interpretativo o aplicativo.

Pero donde más se encuentra expuesto el control de convencionalidad de las leyes a fricciones y contradicciones es en el modelo que lo separa del control de constitucionalidad, en el que pueden darse situaciones conflictivas de manera más acentuada que en los modelos de unificación de control de constitucionalidad y control de convencionalidad. De ahí que no pocos autores estimen más conveniente el modelo concentrado ${ }^{65}$.

\section{El caso español}

En España, donde el Tribunal Constitucional ya es tenido por parte de la doctrina por un Tribunal Supremo ${ }^{66}$, y en vistas de una futurible ratificación del Protocolo 16, sería admisible sin embargo un control difuso de convencionalidad no solo en aplicación de la doctrina del TC sobre la prevalencia de los tratados en caso de conflicto con

65 V. Ferreres Comellas, Una defensa del modelo europeo de control de constitucionalidad, Madrid, Marcial Pons, 2011, p. 208.

66 M. Aragón Reyes, «Problemas del recurso de amparo», Revista jurídica Universidad Autónoma de Madrid, n. ${ }^{\circ} .8,2003$, p. 74 . 
las leyes por su resistencia a ser derogados por éstas ${ }^{67}$, sino también y especialmente por desprenderse así del art. de la Ley 25/2014 de Tratados, cuyo art. 31 impone la prevalencia de los tratados sobre las leyes al disponer que «Las normas jurídicas contenidas en los tratados internacionales válidamente celebrados y publicados oficialmente prevalecerán sobre cualquier otra norma del ordenamiento interno en caso de conflicto con ellas, salvo las normas de rango constitucional». Ahora bien, como se acaba de apuntar, es inequívoca la tendencia casacional del TC en los procesos de tutela de derechos fundamentales y quizás este hecho no deba ser irrelevante a la hora de determinar quién debe ser juez de la convencionalidad de las leyes. De ahí que haya abogado por otorgar el carácter de norma paramétrica al $\mathrm{CEDH}^{68}$, que pasaría a integrar el parámetro del juicio de constitucionalidad mediante su incorporación al art. $161 \mathrm{CE}^{69}$. Entretanto, y a pesar de que en abstracto cabe inaplicar una ley por contradecir un tratado internacional que no afecte a derechos fundamentales, sin embargo, mientras no se modifique la Constitución, a juicio de un sector doctrinal, al juez ordinario le está vedada la competencia para inaplicar una ley cuando la estime contraria al CEDH, rechazando por lo tanto la posibilidad de un control de convencionalidad difuso en la jurisdicción ordinaria. Sostienen estos autores que, en el supuesto del CEDH, puesto que nos encontramos ante un tratado sobre derechos, la concentración del control de convencionalidad de la ley en el TC cabe inferirla directamente de la Constitución, de modo que el juez ordinario estaría obligado al planteamiento de la cuestión de inconstitucionalidad de las leyes que contravengan el CEDH. Añaden que no solo esta modalidad es la aparentemente practicada, sino que además es la única posible a la vista del art 10.2 CE, de modo que ante una ley nacional que vulnere derechos convencionales, el juez ordinario está obligado a plantear la cuestión de inconstitucionalidad, al integrarse el deber de interpretación conforme al Convenio con el deber de interpretación conforme a la Constitución, derivándose de ello que toda ley vulneradora del Convenio lo sería al mismo tiempo de la Constitución ${ }^{70}$. En consecuencia, para esta posición doctrinal, en España los órganos judiciales ordinarios tendrían vedada la inaplicación de una ley supuestamente contraria al $\mathrm{CEDH}^{71}$. En otros casos se ha sostenido que en España se practica un control de convencionalidad «mitigado», del que cabe dudar que se trate de un auténtico control, pues en realidad no es otra cosa que la aplicación de una interpretación conforme que busca, de entre los diversos sentidos atribuibles a la norma interna, aquel que mejor se ajusta al $\mathrm{CEDH}^{72}$.

67 V. Ferreres Comellas «El juez nacional ante los derechos fundamentales europeos. Algunas reflexiones en torno a la idea de diálogo», Sárz Arnárz, A. y Zelaia Garagarza, M.; Integración europea y Poder Judicial, Oñati, IVAP, 2006, p. 250.

68 Bien mediante su inclusión en el bloque de constitucionalidad de las normas (art. 28 LOTC) o bien mediante la constitucionalización del Convenio. R CANOSA USERA, El control de convencionalidad, Civitas-Aranzadi, Cizur Menor, 2015, pp. 127 y 128.

69 En este sentido, García Roca, J. (ed.): Pautas para una reforma constitucional, Cizur Menor, Thomson Reuters-Aranzadi, 2014, p. 35.

70 F. Rubio Llorente, «La relation entre les juridictions espagnoles et les juridictions «européennes», en Renouveau du droit constitutionnel. Mélanges en l'honneur de Louis Favoreu, Paris, Dalloz, 2007, p. 1398.

71 J. García Roca, «El diálogo entre el Tribunal Europeo de Derechos Humanos y los Tribunales constitucionales...", op. cit., p. 209.

72 Vid. P. Nuevo López, «Control de convencionalidad y aplicación judicial de los derechos fundamentales de la Unión Europea», Revista catalana de dret públic, n. ${ }^{\circ} 50$ (junio 2015), p. 148. 
Ahora bien, esta modalidad de control de convencionalidad de las leyes no es, para una parte de la doctrina, la que se desprende de la posición jerárquica de los tratados internacionales resultante del sistema de fuentes instaurado por la propia Constitución, a pesar de que la jurisprudencia constitucional no reconozca abiertamente su supralegalidad, por lo que este otro posicionamiento doctrinal considera que el control de convencionalidad en España sobre leyes que vulneren el CEDH, ha de ser difuso, al menos mientras el TC no cambie su doctrina sobre los tratados ${ }^{73}$, y ello como obligada consecuencia de la posición supralegal de los mismos así como de su prevalencia sobre la ley ex art. 31 de la Ley 25/2014 sobre Tratados, de manera que el control difuso no sería un mero desideratum, sino una verdadera impositio derivada de la propia Constitución española ${ }^{74}$. A mayor abundamiento, la doctrina del TC en torno a los tratados ha venido entendiendo que en caso de una ley contraria a sus disposiciones, se plantea un problema de selección de la ley aplicable, pero no un problema de constitucionalidad. De ahí que quepa que un juez ordinario inaplique una ley por estimarla contraria al $\mathrm{CEDH}^{75}$. Así ha ocurrido en alguna ocasión, si bien de manera todavía tímida ${ }^{76}$. Por contra, y a pesar de que dicha doctrina jurisprudencial parecería en efecto abocar a tal conclusión sobre la competencia del juez para inaplicar una ley inconvencional, los términos del problema cambian cuando los jueces ordinarios interpretan los derechos fundamentales. Dicho de otro modo, el TC, como señala Pérez Sola, carece de potestad para interferir en la función interpretativa judicial, a no ser que en ella puedan quedar afectados derechos fundamentales y libertades públicas, pues en tal caso, la interpretación y aplicación de la norma seleccionada adquiere relevancia constitucional, lo cual quiere decir que, como recuerda el propio TC (STC 103/1990 de 3 de junio), la Constitución «es el contexto obligado al que ha de referirse la aplicación de las leyes, teniendo por ello los jueces y tribunales el deber de ejercer su función jurisdiccional de conformidad con los valores, principios y derechos constitucionales, especialmente en los derechos fundamentales» ${ }^{77}$. Acaso por ello hasta ahora el TC no ha admitido expresamente que los jueces puedan inaplicar leyes que por inconvencionalidad vulneren los derechos del CEDH. Es más, en el caso del Derecho de la UE ha habido pronunciamientos del TC (STC 58/2004, de 19 de abril, STC 194/2006, de 19 de junio) en los que parecía negar la existencia de una competencia propia del juez ordinario para dejar sin aplicación una ley incompatible con sus prescripciones, al exigir, para no entender vulnerado el derecho a la tutela judicial efectiva, el previo planteamiento de la cuestión

73 V. Ferreres Comella, «El juez nacional ante los derechos fundamentales europeos. Algunas reflexiones en torno a la idea de diálogo», A. Sárz Arnáiz, y M. Zelaia Garagarza; Integración europea y Poder Judicial, Oñati, IVAP, 2006, p. 251.

74 L. Jimena QueSADA, Jurisdicción nacional y control de convencionalidad. A propósito del diálogo judicial global y de la tutela multinivel de derechos, Cizur Menor, Thomson-Aranzadi, 2013, pp. 30-31.

75 V. Ferreres Comella, «El juez nacional ante los derechos fundamentales...», p. 250.

76 Se cita como caso más claro de inaplicación de una ley ejerciendo el control de convencionalidad, el de la Sentencia de la Sala de lo Contencioso-Administrativo del Tribunal Superior de Justicia de Andalucía de 4 de marzo de 2008 (recurso n. ${ }^{\circ}$ 787/2007). L. JIMENA QUESADA, «Control de constitucionalidad y control de convencionalidad: ¿un desafío para los Tribunales Constitucionales en la Unión Europea?», en UgarTEMENDía EcEIZABARRENA, J.I. y Jáuregui Bereciartu, G.; Derecho Constitucional europeo, Valencia, Tirant lo Blanch., 2011, p. 310.

77 N. PÉrez Sola «El Tribunal Constitucional como juez de los derechos y la integración de la jurisprudencia del Tribunal Europeo de Derechos Humanos: el estado de la cuestión», PÉrez Tremps, P. (coord.), La reforma del Tribunal Constitucional, Valencia, Tirant lo Blanch, 2008, p. 801. 
prejudicial en supuestos en que no era obligado ${ }^{78}$. Esta doctrina ha sido corregida con posterioridad ante su evidente oposición a la jurisprudencia del TJUE (STC 78/2010, de 20 de octubre, FJ 2).

Pero frente a estas tesis restrictivas sobre la posibilidad de inaplicar leyes inconvencionales, no debe eludirse en la actualidad la cuestión de si el control de convencionalidad hacia el que se siente inclinado el juez ordinario no deba ser la lógica consecuencia del valor unificador que tienen las declaraciones de derechos, como límite que opera frente a cualquier poder público y como criterio inspirador de su actuación. Que cada declaración se vea acompañada por su respectivo sistema de garantías no impide que el juez ordinario trate de guiarse por el criterio de la garantía más favorable, escogiendo la Carta de derechos que mejor se acomode al caso que está conociendo. Parece incuestionable que el reenvío prejudicial previsto en el Protocolo $n .^{\circ} 16$ puede aumentar esa inclinación, poniendo en manos de los altos tribunales una vía más, de entre las varias que tienen a su disposición, para indagar en la garantía más favorable del derecho afectado, lo cual relegará la cuestión de inconstitucionalidad a un remedio más entre los existentes. Ello puede comportar una progresiva marginalidad de la jurisdicción constitucional pues la jurisdicción ordinaria ejerce en estos casos una función cuasi-constitucional ${ }^{79}$.

No cabe entender sin embargo que el control difuso de convencionalidad sea una exigencia que derive del Tratado de la UE, a pesar de la mención al CEDH que efectúa su art. 6. A este respecto resulta necesario referirse a la sentencia Kamberaj del TJUE (C-571/10), en la que se deja claro que el CEDH no ha quedado absorbido por el Derecho europeo tras su recepción en el art. 6 del Tratado, cuyo cometido no es disciplinar el modo de articular las relaciones entre el Convenio europeo y el derecho nacional, sino que se limita a incluirlo como fuente subsidiaria, permitiendo por tanto que el primero conserve su carácter de fuente autónoma. No se puede por tanto, a partir del art. 6 del TUE, deducir que el control de convencionalidad difuso sea una consecuencia derivada del Derecho de la UE, de la que se pueda extraer que las disposiciones convencionales han de compartir la misma primacía que las normas de la Unión, lo que exigiría de los jueces una eventual inaplicación de la ley nacional cada vez que se produzca una antinomia interpretativa irreductible. Tal posibilidad tendría para autores como Ferreres efectos devastadores ${ }^{80}$.

Ahora bien, aun admitiendo que la concentración del control de constitucionalidad y de convencionalidad puede resultar útil a priori para paliar incoherencias y contradicciones, no deja de presentar algunos inconvenientes que es preciso tener en cuenta. De entrada, ambos tipos de control son de naturaleza distinta, ya que las normas de referencia no son las mismas ni cumplen la misma función respecto a la norma objeto de control. No obstante, es cierto que desde un punto de vista material, la superposición de normas podría hacer

78 Se lee por ejemplo en la STC 58/2004 que «el juez no puede, ante la única norma legal aplicable al caso concreto, limitarse a inaplicarla soslayando el procedimiento expresamente establecido para ello en nuestro Ordenamiento jurídico tanto para el planteamiento de la cuestión de inconstitucionalidad prevista en el artículo 163 CE como para el de la cuestión prejudicial recogida en el [anterior] artículo 234 Tratado CE. Tal actuación es contraria al principio de legalidad inherente al Estado de Derecho que la Constitución enuncia en su Título Preliminar (art. 9.3)...»

79 M. Diosola; C. Fasone; I. Spigno, «The Prospective Role of Constitutional Courts in the Advisory Opinion Mechanism Before the European Court of Human Rights: A First Comparative Assessment with the European Union and the Inter-American System», German Law Journal, Vol. 06, n. ${ }^{\circ}$ 06, 2015, p. 1398.

80 V. Ferreres Comella; "Commento», Capuccio, L. - Lamarque, E. (a cura di), Dove va il sistema italiano accentrato di controllo di costituzionalità?, Napoli, Editoriale Scientifica, 2013, p. 325. 
aconsejable una suerte de control de fundamentalidad ${ }^{81}$. A esta solución se le pueden oponer sin embargo una serie de objeciones. Entre otras, la de que no todos los tratados internacionales sobre derechos fundamentales tienen la misma capacidad de irradiación en el derecho interno que la que se predica del texto constitucional, como sucede con la Carta europea de derechos fundamentales, que solo es invocable en el ámbito de aplicación de las normas de Derecho de la UE. Los contornos de cada derecho, fundamental y convencional, pueden asimismo variar, por lo que no siempre pueden resultar coincidentes. Pero sobre todo, lo que no evita la concentración de ambos controles es que la jurisdicción ordinaria pueda a posteriori juzgar de manera distinta a la jurisdicción constitucional, fundándose en una norma internacional distinta o bien como resultado de interpretaciones evolutivas de la ley o de los tratados. Del mismo modo, si el juez ordinario va a seguir sin poder inaplicar una ley inconstitucional, las divergencias seguirán siendo inevitables. Solo si existe un recurso contra las decisiones de los tribunales de la jurisdicción ordinaria ante la jurisdicción constitucional puede eliminarse la dualidad de jurisdicciones. Ello conllevaría instituir un control único de la aplicación jurisdiccional del derecho convencional que solo puede tener lugar si las decisiones de la jurisdicción constitucional se imponen erga omnes al resto de tribunales, asumiendo así el papel de un Tribunal Supremo ${ }^{82}$. La idea, que late no pocas veces, de que bajo el ejercicio de un control de convencionalidad se esconde muchas veces un control de constitucionalidad encubierto quedaría desde luego definitivamente alejada de este modo.

Tal aspiración parece sin embargo no tener en cuenta un cierto realismo que lleva a confutar que deba ser el Tribunal Constitucional el que lleve a cabo un control concentrado, también de la convencionalidad de las leyes, cuando éstas contradigan las disposiciones convencionales. Ni la igualdad en la aplicación de la ley, ni la certeza del derecho como bienes ordinamentales a salvaguardar, pueden ser invocados en cualquier circunstancia como fundamento de una protección centralizada en la jurisdicción constitucional, puesto que la respuesta del juez constitucional puede no ser concluyente en todos los casos en los que el contraste entre normas no exija la nulidad de una disposición legislativa, sino que requiera una adición o la adopción de una norma de acuerdo con los principios del CEDH. En tal caso, si la interpretación sobre cuestiones de principio se encuentra en la jurisprudencia del TEDH, no se ve por qué deba de intervenir la jurisdicción constitucional, pues el juez ordinario no hará nada distinto a lo que ya viene realizando con el Derecho de la $\mathrm{UE}^{83}$. No resulta por tanto superfluo tener que insistir en que la concentración de ambos tipos de control ante el órgano de la jurisdicción constitucional no conduce per se a eliminar este tipo de obstáculos. Además de los que se acaban de mencionar, ya se ha hecho alusión también a la posibilidad de un conflicto entre ley interna y un derecho convencional, cuando sobre la primera haya recaído una declaración de constitucionalidad y sin embargo no sea posible conciliar la interpretación del derecho

$81 \mathrm{~J}$. Andriantsimbazovina, «L'enrichissement mutuel de la protection des droits fondamentaux au niveau européen et au niveau national. Vers un contrôle de «fondamentalité»?», Revue Française de Droit Administratif, n. ${ }^{\circ}$ 1, Janvier-février, 2002, p. 136-138.

82 D. De BÉChILlon, «Plaidoyer pour l'attribution aux juges ordinaires du pouvoir de contrôler la constitutionnalité des lois et la transformation du Conseil constitutionnel en Cour suprême», en Mélanges en l'bonneur de Louis Favoreu, Paris, Dalloz, 2007, p. 109.

83 A. RugGerI, «Ragionando sui possibili sviluppi dei rapporti tra le corti europee e i giudici nazionali (con specifico riguardo all'adesione dell'Unione alla CEDU e all'entrata in vigore del prot. 16)», Rivista AIC, n. ${ }^{\circ} 1 / 2014$, p. 5. 
fundamental en cuestión efectuada por el la jurisdicción constitucional con la aplicación del correlativo derecho convencional según la interpretación realizada por el TEDH, por no derivarse un nivel de protección mayor en la norma fundamental ${ }^{84}$. Desde luego tal hipótesis se revela extremadamente improbable en el caso español, en el que el TC pondera para cada concreto derecho «las fórmulas de articulación y definición más pertinentes, en diálogo constante con las instancias jurisdiccionales autorizadas, en su caso, para la interpretación auténtica de los convenios internacionales que contienen enunciados de derechos coincidentes con los proclamados por la Constitución española» ${ }^{85}$. Puesto que entre tales convenios el CEDH adquiere un valor interpretativo preferente al «erigir a la jurisprudencia del Tribunal de Estrasburgo en denominador común» para una interpretación compartida en su contenido mínimo, no resulta difícil entender que la mayoría de las veces la conciliación a la que está obligado el juez nacional como juez europeo de los derechos fundamentales se verá inmensamente facilitada.

Con todo, aunque la cuestión en torno a la conveniencia o no de un control concentrado de convencionalidad de la ley tenga una indudable incidencia en la coexistencia de múltiples niveles de derechos y a pesar de que afecte de manera importante a los modelos de justicia constitucional concentrada, el impulso al papel del TC como instancia de control de la convencionalidad no tendrá lugar en virtud de su condición de juez de la ley, sino que va a venir exigido por su condición de juez de los derechos. Así pues, la incorporación del TC al nuevo mecanismo prejudicial de carácter consultivo no va a venir, en el caso español, determinada por la existencia de un control concentrado de convencionalidad de la ley que formalmente no existe ${ }^{86}$, sino en virtud de su posición de última instancia jurisdiccional en la tutela de los derechos, siendo por tanto ambas cuestiones claramente deslindables entre $\mathbf{s i ̂}^{17}$. La inclusión del TC entre las más altas instancias jurisdiccionales a efectos del Protocolo n. ${ }^{\circ} 16$ parece así obligada, a pesar de la libertad que en este extremo ha dejado el Protocolo a los estados que pretendan suscribirlo. A ello conduce el que exista un recurso individual por violación de derechos fundamentales que ha de tenerse a estos efectos como último remedio a la hora de agotar las vías jurisdiccionales que exige la subsidiariedad a la que se refiere el art. $13 \mathrm{CEDH}$. Ahora bien, ese grado de instancia más alta en la protección de los derechos no garantiza un recurso al mecanismo prejudicial por parte del TC. Cabría en este punto realizar las mismas consideraciones que ya se utilizan para medir la actitud o predisposición al diálogo de la jurisdicción constitucional en el planteamiento de la cuestión prejudicial al TJUE. Asimismo, la utilización del mecanismo prejudicial se puede ver dificultada por la introducción de mecanismos más exigentes para la admisión del recurso de amparo, hacia cuya objetivación pretendía propender la reforma de la LOTC de la LO 6/2007 o también si no se abre el amparo constitucional

84 P. Pérez Tremps, «La experiencia española de aplicación de las 'Cartas' europeas de Derechos humanos por el Tribunal Constitucional», Fragola, M.; La cooperazione fra Corti in Europa nella tutela dei diritti dell'uomo, Napoli, Editoriale Scientifica, 2012, p. 128; el mismo texto se recogía en ID. «Las «Cartas» y los Tribunales», en AA.VV., Estudios sobre la constitución española, Madrid, Cortes Generales, 2008, p. 2010.

85 DTC 1/2004, de 13 de diciembre, sobre el Tratado por el que se establece una Constitución para Europa, FJ 6.

86 Sin embargo tampoco existe atribución expresa a los tribunales ordinarios de la competencia para inaplicar la ley ejerciendo el control de convencionalidad. R. CANOSA USERA, El control de convencionalidad, op. cit., p. 127.

87 O. Pollicino, «La Corte costituzionale è una «alta giurisdizione nazionale» ai fini della richiesta di parere alla Corte EDU ex Protocollo 16?», Forum di Quaderni Costituzionali, 2/04/2014, p. 3. 
a todos los derechos fundamentales con gemelos convencionales ${ }^{88}$. Una razón de peso que sin embargo puede inclinar al TC a hacer uso de la cuestión prejudicial convencional es que la firmeza de sus decisiones, que no son susceptibles de recurso debido al efecto de cosa juzgada, podría quedar parcialmente desvirtuada ante la posibilidad de un pronunciamiento contrario del TEDH, e incluso, una reforma del recurso de revisión o del de nulidad de actuaciones para convertirlo en vía de ejecución de las sentencias del TEDH, podría implicar que se proceda a rescindir una sentencia del TC por parte del juez ordinario al exigirlo una condena del TEDH, si bien ello exigiría una reforma de la LOTC ${ }^{89}$. Este es por tanto el ámbito natural en donde realmente se puede producir el diálogo con el TEDH, pues permitiría conocer a éste la interpretación no solo de los hechos, sino también del acomodo legal y jurisdiccional tanto al marco del CEDH como al de la jurisprudencia convencional ${ }^{90}$.

Pero si hay un ámbito en el que el nuevo mecanismo de la cuestión prejudicial va a suponer sin duda una acentuación de la capacidad dialógica del juez nacional, ése va a ser el de las instancias superiores de la jurisdicción ordinaria, a las que a partir de ahora se les abre un abanico de mecanismos de diálogo concretados en la posibilidad de plantear hasta una triple cuestión prejudicial si, además de derechos constitucionales, se encuentran implicados derechos de la Carta de la UE y derechos contemplados en el CEDH, lo cual podría abocar al Tribunal ordinario a una triple prejudicialidad mediante la formulación de una cuestión de inconstitucionalidad ante el TC, una cuestión euro-unitaria ante el TJUE y una cuestión convencional ante el TEDH. El problema que se plantea en nuestro ordenamiento es si se debe priorizar una sobre otra o si se debe establecer una prelación.

La posibilidad de una doble o triple prejudicialidad es probablemente una de las situaciones en las que se plantea con toda su agudeza la complejidad procesal de la tutela multinivel de derechos ${ }^{91}$, que no cabe confundir con un fenómeno de duplicidad de jurisdicciones, en el caso que nos ocupa, constitucional y convencional, fenómeno éste último que no es desconocido en nuestro ordenamiento. No obstante, aun siendo distintos, tanto en el fenómeno de la duplicidad o pluralidad de jurisdicciones, como en el de la múltiple prejudicialidad, un mismo objeto litigioso es susceptible de recibir pronunciamientos contradictorios por utilizar un distinto parámetro de enjuiciamiento. En el caso de triple prejudicialidad no estamos ante un fenómeno de duplicación o triplicación de jurisdicciones, ya que el juez nacional nunca conoce sobre un mismo objeto litigioso sobre el que existen dos o tres procesos simultáneos. Pero sí tiene como rasgo en común con éstas el que sobre un mismo objeto puedan recaer pronunciamientos contradictorios. Hecha esa salvedad, podría adoptarse, cuando se invoque en un proceso que una ley lesiona tanto un derecho fundamental como un derecho convencional, sobre la cual el tribunal nacional albergue dudas, la misma solución que nuestro ordenamiento prevé para los casos de concurrencia de jurisdicciones, en concreto para la duplicidad provocada por el concurso tanto de la juris-

88 R. Canosa Usera, El control de convencionalidad, op. cit., p. 128.

89 P. Tenorio SánCHez, «Derechos en serio, recurso de amparo, reordenación de la garantía judicial y reforma de la Ley Orgánica del Poder Judicial», Revista de Derecho Político, n. ${ }^{\circ}$ 88, 2013, p. 133.

90 N. PÉrez Sola, La defensa convencional de los derechos en España. ¿Es posible el diálogo entre Tribunales?, INAP, Madrid, 2015, p. 31.

91 Situación que muchos auguran una fuente de perplejidades e inseguridades. MUÑOZ MACHADO: «Los tres niveles de garantías de los derechos fundamentales en la Unión Europea: Problemas de articulación», RDCE, 2015, p. 209. 
dicción constitucional como de los órganos jurisdiccionales del orden contencioso-administrativo, quienes pueden desenvolver su actividad de manera simultánea especialmente en los procesos de conflictos de competencias ${ }^{92}$, dando origen a una duplicidad que ha tratado de ser paliada instaurando la prejudicialidad del proceso entablado ante el TC cuando la impugnación de un acto o resolución estuviese pendiente de resolución en cualquier otro Tribunal, quien suspenderá el curso del proceso hasta la decisión del conflicto constitucional (art. 61.2 LOTC), a la que queda vinculado (arts. 61.3 LOTC y art. 5.1 LOPJ). Podría ser una de las posibles soluciones a una acumulación de la cuestión prejudicial ante el TEDH con la cuestión de inconstitucionalidad.

Ahora bien, existiría otra vía alternativa, consistente no en priorizar la cuestión de inconstitucionalidad como parece que exigiría el art. $163 \mathrm{CE}$, — que obliga a que ésta se refiera a una disposición legal aplicable —, sino en que la misma pase a tener carácter subsidiario respecto a la cuestión consultiva ante el $\mathrm{TEDH}^{93}$. De este modo, una vez recibida por el tribunal ordinario la interpretación del TEDH de la que se infiera que la ley no vulnera un derecho convencional, el órgano jurisdiccional puede plantear la correspondiente cuestión de inconstitucionalidad ante el TC si estima que en cambio la ley puede estar atentando contra un derecho fundamental. De este modo, la posición del TC se invertiría respecto a la hipótesis de prioridad de la cuestión de inconstitucionalidad, de modo que el control del que se ocuparía no sería probablemente ya, el de constitucionalidad junto al de la convencionalidad de una ley nacional, sino que podría transformarse en un control de la constitucionalidad no solo de la ley, sino del propio CEDH.

Pero existen otros criterios a los que se puede atender para determinar una prelación o prioridad de cuestiones prejudiciales. En primer lugar, se puede adoptar como criterio para la priorización de una cuestión el de seguirse de la resolución de ésta efectos vinculantes para el juez nacional, priorizando entonces la cuestión que produzca efectos de iure frente a la que es meramente consultiva. Se seguiría de ahí que cuestión prejudicial comunitaria y constitucional deben preceder a la cuestión convencional, pues las primeras funcionan como mecanismos uniformadores del Derecho, mientras que la cuestión convencional tiene una lógica distinta, ya que su objeto es potenciar el principio de subsidiariedad. Y entre cuestión comunitaria y cuestión de constitucionalidad, sabemos por lo ya antedicho que esta última nunca podrá vincular su resolución ni provocar la pendencia de la cuestión comunitaria, por lo que cabe simultanear ambas o bien priorizar esta última. Cabe asimismo aplicar el mismo criterio cuando el supuesto sea de doble prejudicialidad y venga dado por la concurrencia entre cuestión comunitaria y cuestión convencional. Seguiría siendo de aplicación el criterio de los efectos vinculantes de iure de la decisión a la cuestión ${ }^{94}$, sin necesidad de justificar la priorización de la cuestión comunitaria interpretando que sería una consecuencia que deriva del propio Tratado de Lisboa, por quedar la cuestión convencional absorbida o subsumida en la cuestión decidida por el Tribunal de Justicia de la UE

92 R. Punset Blanco, «Tribunal Constitucional y órganos judiciales en la tutela de la supremacía de la Constitución. Una perspectiva general», R. PUNSET BlanCo - J. SANTOS Vijande (dirs.), Jurisdicción ordinaria y Tribunal Constitucional, Santiago de Compostela, Escuela Gallega de Administración Pública, 1996, p. 29.

93 Esta propuesta ha sido formulada en el ámbito de la cuestión prejudicial de la UE, por Miguel Azpitarte, para el caso en que la aplicación judicial de una norma de la UE provoque una lesión en un derecho fundamental. M. AzPitarte Sánchez, El Tribunal Constitucional ante el control del Derecho comunitario derivado, Madrid, ThomsonCivitas, 2002, p.133.

94 R. Alonso García El Juez nacional en la encrucijada europea, op. cit., p. 162. 
al aplicar éste el CEDH por mandato del art. 6.3 TUE. Lo que establece dicho precepto, como se ha dicho antes, no es propiamente una absorción del CEDH por el Derecho de la UE, puesto que el reenvío al CEDH no lo convierte en fuente autónoma, sino que tiene cabida como una remisión a los principios del Derecho europeo que solo tiene efectos interpretativos. Cabe asimismo imaginar otro supuesto de doble prejudicialidad producido por el concurso de cuestión convencional y cuestión de constitucionalidad, que podría resolverse priorizando de nuevo la cuestión cuya resolución tiene efectos vinculantes de iure. Pueden citarse no obstante argumentos en apoyo de la priorización de la cuestión prejudicial consultiva frente a la cuestión prejudicial constitucional. Así, constatada una divergencia a consecuencia de la interpretación de las disposiciones convencionales ofrecida por el TEDH, ésta no tiene que llevar necesariamente a un incumplimiento, ya que el estándar de protección que dispensa el marco constitucional puede ser más elevado que el que se deriva del Convenio. De este modo, la jurisdicción constitucional estaría llamada a intervenir en último lugar para examinar si el estándar de protección que establece el marco constitucional es mayor. Esta posibilidad podría ser accionable en aquellos países en los que el control de convencionalidad se ejerce por la jurisdicción constitucional mediante el planteamiento obligatorio de la cuestión de inconstitucionalidad, de modo que podría posibilitar que las altas instancias de la jurisdicción ordinaria, ante la imposibilidad de inaplicar una ley inconvencional, se inclinen por plantear la cuestión prejudicial consultiva al TEDH con carácter previo a la cuestión de inconstitucionalidad ${ }^{95}$. A pesar de que pueda entablarse este diálogo previo entre altos tribunales de la jurisdicción ordinaria y el TEDH, no del todo es probable que en los sistemas concentrados, la jurisdicción constitucional exonere a los tribunales ordinarios de la obligación de plantear la cuestión de inconstitucionalidad.

\section{REFLEXIÓN CONCLUSIVA}

Resulta incuestionable que el reenvío que incorpora el Protocolo 16 puede convertirse en una valiosa herramienta en el proceso de cooperación y propulsión de la coherencia del circuito jurisprudencial construido a partir de la circularidad de interpretaciones conformes de Tribunal Constitucional, Tribunal de Justicia de la UE y TEDH. La inserción de una nueva cuestión prejudicial no traerá por ello consigo una disminución en la autonomía del juez nacional, sino que debe ser vista como una garantía más de la triple tutela de derechos que se superponen y que tiene como regla esencial la del mejor estándar de protección a partir de una disputa discursiva construida sobre la mejor solución.

De igual modo, la puesta en práctica de las consultas prejudiciales al TEDH va a marcar el comienzo de una nueva etapa en la redefinición y reajuste del papel y funciones que ejerce el Tribunal de Estrasburgo ${ }^{96}$. En este sentido, cabe subrayar la destacada contribución que va a suponer el Protocolo 16 en la reorientación del TEDH como jurisdicción constitucional $^{97}$. En línea con esta evolución, aunque el recurso individual ante el TEDH

95 R. CONTI «La richiesta di «parere consultivo» alla Corte europea», op. cit., p. 16.

96 D. Milner, «Protocols no. 15 and 16 to the European Convention of Human Rights in the context of the perennial process of reform: a long and winding road», Zeitschrift für Europarechtliche Studien, 1/2014, p. 50.

97 El TEDH ejerce el control propio de una jurisdicción constitucional puesto que tiene confiado por el art. 19 CEDH un «control europeo», que revisa desde un parámetro que distinto a la norma nacional las decisiones de la 
permanece como pieza clave del sistema convencional, la lógica de reforzamiento de la subsidiariedad que preside los Protocolos n. ${ }^{\circ} 15$ y n. ${ }^{\circ} 16$ puede hacer aconsejable la adopción de mecanismos similares al certiorari que permitan seleccionar los asuntos de mayor trascendencia e importancia. El horizonte sería por tanto el de un Tribunal regulador del conjunto de jurisdicciones europeas en el terreno de los derechos fundamentales.

Sobre el grado de incidencia que la nueva herramienta producirá en lo que se ha dado en llamar la lucha por el poder de interpretación ${ }^{98}$, la cuestión prejudicial convencional no impone del todo un monopolio interpretativo sobre las altas jurisdicciones nacionales, sino que más bien instaura una subsidiariedad tutelada que deja espacio a la construcción de un modelo de diálogo horizontal que no es incompatible con su comprensión a partir de otros esquemas, como los federales, pues aunque formalmente no estemos ante un sistema federal, es trasladable la doctrina de la incorporation, forjada en Estados Unidos tras la incorporación a la Constitución del Bill of Rights federal (XIV. Enmienda), dado que en el caso europeo se pretende asentar una judicial supremacy que impone a las jurisdicciones nacionales la garantía de mínimos del CEDH con independencia de si la violación a los derechos convencionales se ha producido en el seno de una relación jurídica regida o no por el propio ordenamiento ${ }^{99}$. Lo que en todo caso demuestra la evolución del TEDH es que la propia dinámica de las fuentes internacionales no posibilita ya el monopolio interpretativo que en materia de derechos fundamentales se arrogaba en otro tiempo la jurisdicción constitucional. Así pues, un mecanismo como el introducido por el Protocolo n. ${ }^{\circ} 16$, que se sustenta en la subsidiariedad, solo tiene sentido si se explica la relación entre tribunales en términos del better standard, pues de otra manera podrían crearse conflictos como el planteado por nuestro TC en la cuestión prejudicial formulada al TJUE en el asunto Melloni (ATC 86/2011), sobre si la euroorden de detención y entrega de condenados juzgados en ausencia permite condicionar la entrega a la posibilidad de revisar la condena en el estado de destino cuando el reclamado ha sido juzgado en ausencia por un delito grave. Admitir que el estándar nacional pueda superar al del Convenio es consecuencia obligada del art. $53 \mathrm{CEDH}$, que no impone un estándar que derogue, limite o restrinja el contenido y alcance de los derechos fundamentales establecido en el estándar nacional.

Las potencialidades del nuevo Protocolo n. ${ }^{\circ} 16$ no se agotan sin embargo en la institucionalización de un diálogo entre cortes, ya que su función puede ampliarse a otros ámbitos. Por de pronto, el nuevo mecanismo prejudicial puede incidir sobremanera en aquellos sistemas en que exista un sistema de control de convencionalidad difuso, ya que las posibles contradicciones que puedan surgir entre los varios órganos jurisdiccionales nacionales podrán tener en la opinión consultiva del TEDH un indudable punto de referencia. Igualmente los tribunales nacionales van a tener la oportunidad también de anticipar la jurisprudencia del TEDH, puesto que al no tener carácter vinculante la respuesta

jurisdicción constitucional, y se superpone al control de constitucionalidad en virtud de la fuerza de un tratado internacional, asumiendo el mismo carácter que un recurso de amparo. CosTA, J.P.: «La Cour européenne des droits de l'homme est-elle une Cour constitutionnelle?», en AA.VV., Constitutions et pouvoirs. Mélanges en l'bonneur de Jean Gicquel, Paris, Montcrhestien, 2008, p.149.

98 F. Fontanelli - G. Martinico, «Alla ricerca della coerenza: le tecniche del 'dialogo nascosto’ fra i giudici nell'ordinamento costituzionale multilivello», Rivista Trimestrale di Diritto Pubblico, vol. 58, n. ${ }^{\circ}$ 2, 2008, p. 385.

99 D. Szymczak, La Convention européenne de Droits de l'Homme et le juge constitutionnel national, Bruxelles, Bruylant, 2007, p. 672. 
recibida a la cuestión prejudicial, de plantearse un recurso individual por una de las partes, el TEDH contará con una valiosa contribución en el examen del derecho nacional que podría influir en la resolución del recurso. En el caso español, la cuestión prejudicial servirá además para disponer de un instrumento adicional, como ya sucede con el TJUE, para dar mejor efectividad al art. 10.2 CE.

TITLE: Strengthening the dialogue between courts and the triple preliminary reference procedure in the protection of fundamental rights: about protocol no. 16 of the ECHR

ABSTRACT: The adoption of the Protocols 15 and 16 to the ECHR has completed a new process of reflection on the shortcomings and transformations that the protection system of the European Convention on Human Rights will face in the coming decades. The new protocol, named the "protocol of dialogue», incorporates a novel «incidental procedure of dialogue» in the framework of the conventionality control, a procedure in addition to preliminary questions which already exist under European Union law $(E U)$ and in the framework of constitutional control. This article aims to address particular reference to the increasing complexity that Conventional preliminary procedure will bring in those systems in which there are a preliminary question of constitutionality and the preliminary reference procedure on the interpretation of $E U$ law. The preliminary reference procedure enacted by Protocol 16 can become a valuable tool in the process of cooperation and coherence propulsion of jurisprudential circuit, built from the circularity of conforming interpretations of the Constitutional Court, Court of Justice of the $E U$ and ECtHR. The new preliminary question will not bring a reduction in the autonomy of national jurisdiction, but should be seen as a further guarantee of the triple protection of rights that overlap and whose essential rule is «the best standard of protection» from the starting point of a discursive argument founded on the best solution.

RESUMEN: La adopción de los Protocolos 15 y 16 ha culminado un nuevo proceso de reflexión sobre las deficiencias y transformaciones que habrá de afrontar en los próximos decenios el sistema de protección del Convenio Europeo de Derechos Humanos. El nuevo Protocolo, bautizado el Protocolo 16 como el «protocolo del diálogo» incorpora una novedosa «vía incidental de diálogo» en el marco del control de convencionalidad, vía que viene a sumarse a las vías incidentales ya existentes en el marco de los controles de incidentales en aplicación del Derecho de la Unión Europea (UE) y en el marco del control de constitucionalidad. Este artículo dedica especial atención a la creciente complejidad de cuestión prejudicial convencional traerá en aquellos sistemas en los que hay una cuestión previa de constitucionalidad y la cuestión prejudicial en virtud del Derecho de la UE. El reenvio que incorpora el Protocolo 16 puede convertirse en una valiosa herramienta en el proceso de cooperación y propulsión de la coherencia del circuito jurisprudencial construido a partir de la circularidad de interpretaciones conformes de Tribunal Constitucional, Tribunal de Justicia de la UE y TEDH. La inserción de una nueva cuestión prejudicial no traerá por ello consigo una disminución en la autonomía del juez nacional, sino que debe ser vista como una garantía más de la triple tutela de derechos que se superponen y que tiene como regla esencial la del mejor standard de protección a partir de una disputa discursiva construida sobre la mejor solución.

KEY WORDS: Protocol 16, Control of conventionality, European Convention on Human Rights, Preliminary reference, Multilevel protection of human rights

Palabras Clave: Protocolo 16, Control de convencionalidad, Convenio europeo de Derechos Humanos, Cuestión prejudicial, Tutela multinivel de derechos

FECHA DE RECEPCIÓN: 15.01.2018

FECHA DE ACEPTACión: 13.09.2018

UNED. Teoría y Realidad Constitucional, núm. 42, 2018, pp. 453-482 